\title{
Consolidation Analysis of Soft Ground Improved by Stone Columns
}

\section{Incorporating Foundation Stiffness}

\author{
Pei Tai \\ $\mathrm{PhD}$ (Wollongong) \\ Postdoctoral Research Fellow, Department of Civil and Environmental Engineering, School of \\ Engineering, The Hong Kong University of Science and Technology, Clear Water Bay, \\ Kowloon, Hong Kong

\section{Buddhima Indraratna} \\ $\mathrm{PhD}$ (Alberta), MSc (Lond.), BSc (Hons., Lond.), DIC, FIEAust., FASCE, FGS \\ Distinguished Professor of Civil Engineering, Faculty of Engineering and Information \\ Sciences, \\ Director, Centre for Geomechanics and Railway Engineering; University of Wollongong, \\ Wollongong City, NSW 2522, Australia

\section{Cholachat Rujikiatkamjorn} \\ BEng (Hons), MEng (AIT), PhD (Wollongong) \\ Associate Professor of Civil Engineering, Centre for Geomechanics and Railway Engineering, \\ Faculty of Engineering and Information Sciences, University of Wollongong, Wollongong \\ City, NSW 2522, Australia
}

Author for correspondence:

Prof. B. Indraratna

Faculty of Engineering

University of Wollongong

Wollongong, NSW 2522, Australia.

$\mathrm{Ph}: \quad+61242213046$

Fax: +61 242213238

Email: indra@uow.edu.au

Submitted to: International Journal of Geomechanics (ASCE) 

Stone Columns Incorporating Foundation Stiffness

3 Abstract

4 The consolidation of soft ground improved by stone columns is normally analysed

5 under equal strain or free strain conditions. In this study a new consolidation model

6 for stone columns is proposed to capture actual field conditions that lie between these

7 two hypotheses, where a permeable foundation layer on top of the unit cell is

8 introduced. By considering the stiffness of this layer, a closed-form solution can be

9 derived, which indicates a considerable difference between the equal strain and free

10 strain conditions. The influence of foundations with varying values of stiffness is

11 examined, and the results demonstrate that as the foundation layer becomes stiffer, the

12 time needed to achieve a $90 \%$ degree of consolidation decreases and so does the

13 differential settlement, but the steady stress concentration ratio increases. This is also

14 confirmed by a parametric study carried out under varying dimensionless ratios with

15 respect to soil modulus, column spacing and permeability. A computational example

16 is provided to show the implications of these results on actual design. Finally, a case

17 study is presented to illustrate that the proposed model is able to provide more

18 realistic predictions of settlement and stress concentrations on top of the unit cell. 
1 Keywords: consolidation, stone column, differential settlement, stress concentration 2 


\section{$1 \quad$ Introduction}

2 Conventional radial consolidation theory was first proposed by Barron (1948), to

3 describe the cases of equal strain and free strain. For a unit cell which consists of

4 homogeneous soil, equal strain condition assumes that the vertical strain is always

5 uniform at a given depth as consolidation progresses, and therefore, the vertical stress

6 on top of the unit cell is uneven. However, free strain condition imposes a uniform

7 vertical stress at the top surface that results in differential settlement as consolidation

8 takes place. Over the years, various solutions for radial consolidation with vertical

9 drains have been developed by adopting these two concepts (Hansbo et al., 1981; Lei et

10 al., 2015; Leo, 2004; Rujikiatkamjorn and Indraratna, 2014; Tang and Onitsuka, 1998;

11 Walker and Indraratna, 2006; Zhu and Yin, 2001). For flexible prefabricated vertical

12 drains, any difference in the average degree of consolidation based on either condition

13 is found to be small, i.e., often within 5\% (Richart, 1959; Zhu and Yin, 2004).

14 Therefore, when designing vertical drains, either equal strain or free strain condition

15 can be adopted.

16 For cases with stone columns, Han and Ye (2001) proposed a simplified method to

17 estimate the average degree of consolidation of ground reinforced with stone columns

18 that incorporates both well-resistance and soil disturbance. The behaviour of such a

19 composite ground under time-dependent loading has been studied adopting an 
1 analytical approach by Wang (2009), while solutions that incorporate column

2 deformation as well as combined vertical and radial flow have been discussed by Xie et

3 al. (2009) and Lu et al. (2010). Indraratna et al. (2013) proposed a numerical solution

4 for soft soil improved with stone column based on free strain by considering the effects

5 of arching and clogging. Despite these efforts, there is still a large disparity among the

6 aforementioned solutions, which clearly implies that when assumptions of equal strain

7 and free strain are applied to a relatively stiff stone column system there can be a

8 significant deviation (Han, 2014). Moreover, significant differential settlement which

9 is likely to occur for nonuniformly distributed loading condition (Bouassida and Carter,

10 2014) also needs to be considered carefully.

11 In this paper, a modified consolidation model is presented where a theoretical condition

12 between equal strain and free strain that captures the foundation stiffness is described.

13 A closed-form analytical solution is obtained to calculate the average degree of

14 consolidation, the redistribution of vertical stress, and the differential settlement

15 between the column and the surrounding soil, supported by an illustrated example and a

16 case study. A parametric study is also carried out to evaluate the effect of foundation

17 stiffness. 


\section{Establishment of theoretical model}

\section{Basic assumptions}

3 Unlike flexible vertical drains, the difference between the stiffness of a stone column

4 and soil can lead to redistribution of stress and differential settlement between the top

5 of the column and the soil, therefore, an assumption of either free strain or equal strain

6 can be unrealistic. In order to address this dilemma, a mathematical model is proposed,

7 where an additional layer is added on top of the original unit cell to represent the

8 foundation or platform (Figure 1).

9 The proposed model is based on the following assumptions:

10 1) Darcy’s law is valid.

11 2) Only vertical flow is considered inside the stone column, while only radial flow

12 is accounted in the surrounding clay.

13 3) The top surface of the unit cell is free draining, but the bottom and the unit cell

14 boundary are impermeable.

15 4) The load on top of the foundation is uniform and time independent (constant),

16 and only the vertical strains are considered.

17 5) The pore water pressure and flow velocity are continuous across the 18 column-soil interface. 
6) The weight of the foundation layer and its compression are ignored.

7) Any possible shear stress at the column-soil interface is ignored while the shear stress in the foundation layer is calculated using a method that is analogous to the "trapdoor theory" by Terzaghi (1943) as elaborated later.

5 As shown in Figure 1, column settlement at the top surface of the unit cell can be treated

6 as uniform, whereas the actual settlement on top of the surrounding soil depends on the

7 radial distance (i.e., closer to the column means less settlement). The average vertical

8 strains of the stone column $\left(\varepsilon_{c}\right)$ and the surrounding soil $\left(\varepsilon_{s}\right)$ are used after being

9 determined from:

$$
\begin{aligned}
& m_{v s} \frac{\partial\left[\sigma_{S}(t)-\bar{u}_{s}(z, t)\right]}{\partial t}=\frac{\partial \varepsilon_{s}(z, t)}{\partial t} \\
& m_{v c} \frac{\partial\left[\sigma_{c}(t)-\bar{u}_{c}(z, t)\right]}{\partial t}=\frac{\partial \varepsilon_{c}(z, t)}{\partial t}
\end{aligned}
$$

10 where $\sigma_{c}$ and $\sigma_{s}$ are the vertical stresses on top of the stone column and surrounding soil,

11 respectively (no attenuation with depth), $\bar{u}_{c}$ and $\bar{u}_{s}$ are the average excess pore

12 pressure in the stone column and surrounding soil, respectively, and $m_{v c}$ and $m_{v s}$ are the

13 coefficients of volume compressibility of the stone column and surrounding soil, 14 respectively. 


\section{Consideration of the foundation stiffness}

2 The shear stress generated in the foundation layer may differ depending on the type of

3 foundation material (e.g. concrete, sandy soil, or asphalt), and the nature of vertical

4 stress redistribution such as arching; the latter often attracts a variety of opinions when

5 included in modelling (Low et al., 1994; Madhav and Van Impe, 1994; Van Eekelen et

6 al., 2013). In this study, shear stress at the overlying foundation is calculated based on

7 the "trapdoor theory" initially proposed by Terzaghi (1943). It is assumed that when

8 differential settlement occurs, any sliding in the foundation layer is vertical and the

9 normal stress is uniform (Tien, 1996) as shown in Figure 2(a); this assumption has also

10 been adopted in pile-embankment analysis (Chen et al., 2008). The generation of shear

11 stress in the foundation layer is determined by mimicking a traditional direct shear test.

12 A typical curve of shear stress versus the horizontal strain in a direct shear test is shown

13 in Figure 2(b) (Ishibashi, 2011; Schofield and Wroth, 1968), and similarly, the shear

14 stress $(\tau)$ at the sliding surface is related to the normal stress $\left(\sigma_{\mathrm{h}}\right)$ and the differential

15 settlement $(\Delta S)$. Given that the allowable differential settlement of a foundation is

16 usually restricted, it is reasonable to consider that the stress-strain curve would still be

17 in the linear stage. Therefore, in the proposed model, shear stress in the foundation

18 layer is assumed to be linearly proportional to its vertical strain. The slope of the

19 stress-strain curve in a direct shear test defines its shear resistance, whereas in this 
1 model the slope of shear stress versus normalised differential settlement, $\Delta S / H_{l}$, is

2 introduced as the stiffness of the foundation, denoted as $K$. This straight-forward way of

3 considering shear stress may not reflect the real mechanism, but its simplicity enables

4 the following coupled analysis to be carried out effectively.

5 By considering the force equilibrium in the foundation layer, the loads on top of the

6 embankment should be equal to the supporting force provided at the top surface of the

7 unit cell. The redistribution of vertical stress can then be calculated as follows ((3-5):

$$
\begin{gathered}
\pi\left(r_{s}^{2}-r_{c}^{2}\right) \sigma_{s}(t)=\pi\left(r_{s}^{2}-r_{c}^{2}\right) \sigma-\Delta \sigma \cdot H_{1} \cdot \pi r_{c} \\
\pi r_{c}^{2} \sigma_{c}(t)=\pi r_{c}^{2} \sigma+\Delta \sigma \cdot H_{1} \cdot \pi r_{c} \\
\frac{\int_{0}^{H} \varepsilon_{S}(z, t) d z-\int_{0}^{H} \varepsilon_{c}(z, t) d z}{H_{1}} K=\Delta \sigma
\end{gathered}
$$

8 where $r_{c}$ and $r_{s}$ are the radius of the stone column and unit cell respectively, $H_{l}$ is the

9 thickness of the foundation layer, $K$ is the stiffness of the foundation, and $\Delta \sigma$ is the

10 shear stress in the foundation layer.

11 The relationship between vertical strain and excess pore pressure can be represented by

12 (6) and (7), and a detailed derivation is given in Appendix I. Through these two

13 equations, the vertical strains can be calculated independent of the thickness of the

14 foundation layer. 


$$
\begin{aligned}
\frac{\partial \varepsilon_{s}}{\partial t} & =\frac{m_{v c} m_{v s} K H r_{c}^{2} \frac{\partial \bar{u}_{c}}{\partial t}-m_{v s}\left(r_{c}^{2}-r_{s}^{2}\right)\left(m_{v c} H K+r_{c}\right) \frac{\partial \bar{u}_{s}}{\partial t}}{r_{c}^{2}\left[K H\left(m_{v c}-m_{v s}\right)+r_{c}\right]-r_{s}^{2}\left(r_{c}+m_{v c} K H\right)} \\
\frac{\partial \varepsilon_{c}}{\partial t} & =\frac{m_{v c} r_{c}\left(m_{v s} K H r_{c}+r_{s}^{2}-r_{c}^{2}\right) \frac{\partial \bar{u}_{c}}{\partial t}+m_{v c} m_{v s} K H\left(r_{s}^{2}-r_{c}^{2}\right) \frac{\partial \bar{u}_{s}}{\partial t}}{r_{c}^{2}\left[K H\left(m_{v c}-m_{v s}\right)+r_{c}\right]-r_{s}^{2}\left(r_{c}+m_{v c} K H\right)}
\end{aligned}
$$

1 where $H$ is the thickness of the unit cell.

\section{Governing equations}

3 Deformation of the stone column and surrounding clay should be equal to the net flow

4 into the system. Based on deformation-flow equilibrium, the governing equations for

5 the consolidation of clay and column can be established, as represented by (8) and (9),

6 respectively.

$$
\begin{gathered}
\frac{1}{\gamma_{w} r} \frac{\partial}{\partial r}\left(k_{s} f(r) r \frac{\partial u_{s}}{\partial r}\right)=-\frac{\partial \varepsilon_{s}}{\partial t} \\
\left.\frac{2 k_{s}}{\gamma_{w} r_{c}} \frac{\partial u_{s}}{\partial r}\right|_{r=r_{c}}+\frac{k_{c}}{\gamma_{w}} \frac{\partial^{2} \bar{u}_{c}}{\partial z^{2}}=-\frac{\partial \varepsilon_{c}}{\partial t}
\end{gathered}
$$

7 where $u_{s}$ is the pore water pressure of a certain point in surrounding soil, $f(r)$ is a

8 function of radius that describes variations in permeability in the surrounding soil

9 which can used to represent the smear effect, $k_{c}$ and $k_{s}$ are the coefficients of

10 permeability of the stone column and undisturbed soil respectively, and $\gamma_{w}$ is the unit

11 weight of water.

12 The boundary conditions are given by (13), thus: 


$$
\begin{gathered}
\left.\frac{\partial u_{s}}{\partial r}\right|_{r=r_{s}}=0 \\
u_{s}=\bar{u}_{c}\left(r=r_{c}\right) \\
\bar{u}_{s}(0, t)=\bar{u}_{c}(0, t)=0 \quad(t>0) \\
\frac{\partial \bar{u}_{s}(H, t)}{\partial z}=\frac{\partial \bar{u}_{c}(H, t)}{\partial z}=0
\end{gathered}
$$

1 The excess pore water pressure at the top surface of the unit cell is prescribed by the

2 following: when vertical loads are first applied the induced excess pore water pressure

3 is assumed to be uniform in the unit cell and equal to the magnitude of external loads,

4 but when consolidation commences the excess pore pressure is immediately dissipated

5 to zero at the surface of the unit cell.

6 The initial condition can then be expressed by (14), hence:

$$
\bar{u}_{s}(z, 0)=\bar{u}_{c}(z, 0)=\sigma
$$

7 Finally, a governing equation specifying the variable, $\bar{u}_{c}$, can be obtained, and the

8 details of its derivation are given in Appendix II extending the past procedures (Lu et

9 al., 2010; Tai et al., 2017).

$$
C \cdot E \frac{\partial^{3} \bar{u}_{c}}{\partial z^{2} \partial t}-E \frac{\partial^{2} \bar{u}_{c}}{\partial z^{2}}+(B+C \cdot D) \frac{\partial^{2} \bar{u}_{c}}{\partial t^{2}}+(1-D) \frac{\partial \bar{u}_{c}}{\partial t}=0
$$




\section{Analytical solutions}

2 It is assumed that the excess pore water pressure in the stone column can be rewritten as

3 a product of two independent functions (16), each with only one variable. Then, the

4 governing equation obtained can be solved by the variable separation method, where:

$$
\bar{u}_{c}=G(t) \cdot Z(z)
$$

5 The governing equation can now be transformed into two ordinary differential

6 equations (ODEs) as shown below:

$$
-\frac{(B+C \cdot D) G^{\prime \prime}(t)+(1-D) G^{\prime}(t)}{C \cdot E \cdot G^{\prime}(t)-E \cdot G(t)}=\frac{Z^{\prime \prime}}{Z}=-\alpha^{2} \quad(\alpha>0)
$$

7 where $\alpha$ is a positive constant that will be explained later.

\section{General solution}

9 By considering Eqn. (17) as a second order linear ODE, its boundary condition and

10 initial condition are represented by:

$$
\begin{gathered}
\bar{u}_{c}(0, t)=G(t) Z(0)=Z(0)=0 \\
\bar{u}_{c}(z, 0)=G(0) Z(z)=\sigma \\
\frac{\partial \bar{u}_{c}(h, t)}{\partial z}=G(t) Z^{\prime}(H)=Z^{\prime}(H)=0
\end{gathered}
$$

11 The solutions can then be obtained after finding Eigenfunctions based on the variable

12 separation method (Kreyszig, 1988). 


$$
\begin{gathered}
\bar{u}_{c}=\sum_{n} G(t) \cdot Z(z) \quad(n=1,2,3, \ldots) \\
Z_{n}(z)=\sin \left(\alpha_{n} \mathrm{z}\right) \\
G_{n}(t)=b_{n} \mathrm{e}^{\beta_{n} \cdot t}+c_{n} \mathrm{e}^{\theta_{n} \cdot t} \\
\beta_{n}=\frac{-1+D+C E \alpha_{n}^{2}-\sqrt{-4(B+C D) E \alpha_{n}^{2}+\left(1-D-C E \alpha_{n}^{2}\right)^{2}}}{2(B+C D)} \\
\theta_{n}=\frac{-1+D+C E \alpha_{n}^{2}+\sqrt{-4(B+C D) E \alpha_{n}^{2}+\left(1-D-C E \alpha_{n}^{2}\right)^{2}}}{2(B+C D)}
\end{gathered}
$$

1 In the above, the coefficients " $b_{n}$ ", and " $c_{n}$ " are integration constants.

2 The excess pore water pressure in the stone column and surrounding soil can be written

3 respectively as follows:

$$
\begin{gathered}
\bar{u}_{c}=\sum_{1}^{n}\left(b_{n} \mathrm{e}^{\beta_{n} \cdot t}+c_{n} \mathrm{e}^{\theta_{n} \cdot t}\right) \sin \left(\alpha_{n} \mathrm{z}\right) \\
\bar{u}_{s}=\sum_{1}^{n}\left[b_{n}\left[1+(C D+B) \beta_{n}-C E \alpha_{n}^{2}\right] \mathrm{e}^{\beta_{n} \cdot t}\right. \\
\left.+c_{n}\left[1+(C D+B) \theta_{n}-C E \alpha_{n}^{2}\right] \mathrm{e}^{\theta_{n} \cdot t}\right] \sin \left(\alpha_{n} \mathrm{z}\right)
\end{gathered}
$$

4 In Eqn. (27) and (28), these two integration constants, $b_{n}$ and $c_{n}$, can be determined by

5 considering the initial condition ((14), hence:

$$
b_{n}=\frac{\sigma\left(-1+D-C E \alpha_{n}^{2}+\sqrt{-4(B+C D) E \alpha_{n}^{2}+\left(1-D-C E \alpha_{n}^{2}\right)^{2}}\right)}{\alpha_{n} H \sqrt{-4(B+C D) E \alpha_{n}^{2}+\left(1-D-C E \alpha_{n}^{2}\right)^{2}}}
$$




$$
c_{n}=\frac{\sigma\left(1-D+C E \alpha_{n}^{2}+\sqrt{-4(B+C D) E \alpha_{n}^{2}+\left(1-D-C E \alpha_{n}^{2}\right)^{2}}\right)}{\alpha_{n} H \sqrt{-4(B+C D) E \alpha_{n}^{2}+\left(1-D-C E \alpha_{n}^{2}\right)^{2}}}
$$

1 The average degree of consolidation for the whole unit cell, $\bar{U}$, can then be calculated

2 using:

$$
\bar{U}=1-\frac{\left(1-\frac{r_{c}^{2}}{r_{s}^{2}}\right) \bar{u}_{s}+\frac{r_{c}^{2}}{r_{s}^{2}} \bar{u}_{c}}{\sum_{1}^{n} \alpha_{n} \sin \left(\alpha_{n} \mathrm{z}\right) \sigma H}
$$

3 The vertical strains of stone column and surrounding soil can be calculated according to

4 (6) and (7) together with the initial condition, which gives:

$$
\begin{gathered}
\varepsilon_{s}=\frac{m_{v c} m_{v s} K H r_{c}^{2}\left(\bar{u}_{c}-\sigma\right)-m_{v s}\left(r_{c}^{2}-r_{s}^{2}\right)\left(m_{v c} H K+r_{c}\right)\left(\bar{u}_{s}-\sigma\right)}{r_{c}^{2}\left[K H\left(m_{v c}-m_{v s}\right)+r_{c}\right]-r_{s}^{2}\left(r_{c}+m_{v c} K H\right)} \\
\varepsilon_{c}=\frac{m_{v c} r_{c}\left(m_{v s} K H r_{c}+r_{s}^{2}-r_{c}^{2}\right)\left(\bar{u}_{c}-\sigma\right)+m_{v c} m_{v s} K H\left(r_{s}^{2}-r_{c}^{2}\right)\left(\bar{u}_{s}-\sigma\right)}{r_{c}^{2}\left[K H\left(m_{v c}-m_{v s}\right)+r_{c}\right]-r_{s}^{2}\left(r_{c}+m_{v c} K H\right)}
\end{gathered}
$$

5 The stress concentration ratio, $n_{s}$, can now be calculated from:

$$
n_{s}(t)=\frac{m_{v s} \int_{0}^{H} \varepsilon_{c}(z, t) d z+m_{v c} m_{v s} \int_{0}^{H} \bar{u}_{c}(z, t) d z}{m_{v c} \int_{0}^{H} \varepsilon_{s}(z, t) d z+m_{v c} m_{v s} \int_{0}^{H} \bar{u}_{s}(z, t) d z}
$$

6 The differential settlement on the top surface of the unit cell, $\Delta S$, now becomes:

$$
\Delta S(t)=\int_{0}^{H} \varepsilon_{S}(z, t) d z-\int_{0}^{H} \varepsilon_{c}(z, t) d z
$$




\section{Equal strain condition}

2 The equal strain hypothesis is valid when the stiffness of the foundation approaches

3 infinity $(K \rightarrow+\infty)$, and there is no differential settlement occurring during the whole

4 consolidation process.

5 This means the governing equation can degenerate into the form shown below,

6 whereby:

$$
\begin{gathered}
C E \frac{\partial^{3} \bar{u}_{c}}{\partial z^{2} \partial t}-E \frac{\partial^{2} \bar{u}_{c}}{\partial z^{2}}+(1-D) \frac{\partial \bar{u}_{c}}{\partial t}=0 \\
\bar{u}_{s}=\bar{u}_{c}+C E \frac{\partial^{2} \bar{u}_{c}}{\partial z^{2}} \\
\frac{\partial \varepsilon_{s}}{\partial t}=\frac{\partial \varepsilon_{c}}{\partial t}=-\frac{r_{c}^{2} \frac{\partial \bar{u}_{c}}{\partial t}+\left(r_{s}^{2}-r_{c}^{2}\right) \frac{\partial \bar{u}_{s}}{\partial t}}{\left(r_{s}^{2}-r_{c}^{2}\right) / m_{v s}+r_{c}^{2} / m_{v c}}
\end{gathered}
$$

$7 \quad$ Note that the secondary differential item for time has been cancelled, so the two ODEs

8 after variable separation become:

$$
\frac{(D-1) G^{\prime}(t)}{C \cdot E \cdot G^{\prime}(t)-E \cdot G(t)}=\frac{Z^{\prime \prime}}{Z}=-\alpha^{2}(\alpha>0)
$$

9 Through a similar procedure as obtaining the general solution, the solutions for the

10 average excess pore pressure and vertical strain of a unit cell under equal strain

11 condition can be derived as:

$$
\bar{u}_{c}=\sum_{1}^{n} \frac{2 \sigma r_{s}^{2}}{H\left[C E \alpha_{n}^{3}\left(r_{c}^{2}-r_{s}^{2}\right)+\alpha_{n} r_{s}^{2}\right]} e^{\frac{E \alpha_{n}^{2} t}{-1+D+C E \alpha_{n}^{2}}} \sin \left[\alpha_{n} z\right]
$$




$$
\begin{gathered}
\bar{u}_{s}=\left(1-C E \alpha_{n}^{2}\right) \bar{u}_{c} \\
\varepsilon_{s}=\varepsilon_{c}=-\frac{r_{c}^{2} \bar{u}_{c}+\left(r_{s}^{2}-r_{c}^{2}\right) \bar{u}_{s}-\sigma r_{s}^{2}}{\left(r_{s}^{2}-r_{c}^{2}\right) / m_{v s}+r_{c}^{2} / m_{v c}}
\end{gathered}
$$

1 The stress concentration ratio can still be determined using Eqn. (34).

\section{Free strain condition}

3 The free strain hypothesis means that the stiffness of the foundation is negligible and

4 the vertical stress on top of the unit cell is uniform. Consequently, the differential

5 settlement only depends on the compression modulus of stone column and the

6 surrounding soil, hence:

$$
\begin{aligned}
& m_{v s} \frac{\partial\left(\sigma-\bar{u}_{s}\right)}{\partial t}=\frac{\partial \varepsilon_{s}}{\partial t} \\
& m_{v c} \frac{\partial\left(\sigma-\bar{u}_{c}\right)}{\partial t}=\frac{\partial \varepsilon_{c}}{\partial t}
\end{aligned}
$$

7 The structure of the degenerated equation for free strain is still the same as that of the

8 general form, but with the two parameters B and K equalling zero, as represented by

9 Eqns. (45)-(46). Therefore, the solution remains the same as the general one given

10 earlier.

$$
\begin{gathered}
C \cdot E \frac{\partial^{3} \bar{u}_{c}}{\partial z^{2} \partial t}-E \frac{\partial^{2} \bar{u}_{c}}{\partial z^{2}}+C \cdot D \frac{\partial^{2} \bar{u}_{c}}{\partial t^{2}}+(1-D) \frac{\partial \bar{u}_{c}}{\partial t}=0 \\
\bar{u}_{s}=\bar{u}_{c}+C \cdot D \frac{\partial \bar{u}_{c}}{\partial t}+C \cdot E \frac{\partial^{2} \bar{u}_{c}}{\partial z^{2}}
\end{gathered}
$$




\section{Comparison with previous studies}

2 In order to verify the proposed model, comparisons are made with existing

3 consolidation models under the hypotheses of equal strain (Han and Ye 2001, Lu et al.

4 2010) and free strain (Indraratna et al. 2013).

5 The basic parameters adopted in the verification are cited from Indraratna et al. (2013)

6 and presented in Table 1. The smear effect can be considered by the permeability

7 variation funtion $f(r)$ in Eqn. (8), but the effect of clogging in the stone column is

8 ignored. Meanwhile, the time factor, $T$, is adopted as the abscissa that can be defined as

9 shown below.

$$
T=\frac{k_{s} t}{4 m_{v s} \gamma_{w} r_{s}^{2}}
$$

10 Figure 3 shows the comparison of the average degree of consolidation for a unit cell

11 calculated using the proposed model with previous studies. The difference among the

12 three curves of equal strain is negligible, which indicates that ignoring vertical flow in

13 the surrounding soil and radial flow in the column is acceptable for a thick unit cell

$14(>16 \mathrm{~m})$. However, with free strain, the consolidation predicted by the current model is

15 much faster when the time factor is less than 0.1 ; the trend then reverses, and the degree

16 of consolidation given by Indraratna et al. (2013) becomes higher at the later stage. 


\section{Differences between equal strain and free strain}

2 The curves in Figure 3 also show that the degree of consolidation for free strain is

3 higher than that for equal strain at the beginning, but then it falls behind at a later stage.

4 This observation agrees with the statement made by Zhu and Yin (2004), except that the

5 difference is rather small $(<6 \%)$ for vertical drains in their analysis, whereas it can be

6 up to $15 \%$ for stone columns. It can be concluded that, there is a large disparity in the

7 consolidation rate of ground improved by stone columns that results from the basic

8 hypotheses: whether equal strain or free strain is adopted.

9 There is also no redistribution of vertical stresses on top of the column and surrounding

10 soil under free strain conditions, so the stress concentration ratio is always equal to 1 ,

11 whereas the distribution of vertical stress for equal strain changes as consolidation

12 progresses, as shown in Figure 4(a). Initially, most of the vertical loading is carried by

13 the surrounding soil, so the vertical stress ratio on top of the stone column remains at a

14 relatively low level, while the vertical stress ratio on the surrounding soil is larger than

15 unity to maintain the force equilibrium. As consolidation continues, the vertical stress

16 in the surrounding clay decreases while that on the stone column increases, and this

17 agrees with the findings of Han and Ye (2001). Meanwhile, because of the assumption

18 of equal strain, the stress concentration ratio will increase with consolidation until it 
1 reaches the same value as the compressibility ratio of the column material to the soil

2 (i.e., 7 in this case), as shown in Figure 4(b).

3 The evolution of excess pore pressure in the surrounding soil and stone column under

4 both hypotheses is presented in Figure 5(a) and 5(b), respectively. In the surrounding

5 soil the initial excess pore pressure is higher, and its dissipation is faster for the case of

6 equal strain. On the contrary, for the pore pressure in the stone column, the initial value

7 under free strain is markedly higher than that of equal strain, but the difference between

8 equal strain and free strain quickly becomes negligible.

9 Figure 6 gives the profiles of excess pore pressure at different times for stone column

10 and surrounding soil, respectively. Echoing with Figure 5, Figure 6 also shows that the

11 initial excess pore pressure decreases with depth in the surrounding soil, but it increases

12 with depth in the stone column. It is also indicated that more time is required for the

13 completion of consolidation under free strain conditions. When consolidation

14 commences $(\mathrm{T}=0.001)$, the excess pore pressure ratio at the bottom of stone column is

15 almost 0.8 for free strain and less than 0.4 for equal strain (Figure 6a), but after a short

16 period of time $(\mathrm{T}=0.1)$, the pore pressure ratio in the stone column decreases to about

170.2 for both equal strain and free strain. Unlike equal strain, the amount of pore

18 pressure dissipated in stone column is much higher for free strain when the time factor

19 reaches 0.01 , which explains why the degree of consolidation under free strain is higher 
1 initially. The initial excess pore pressure ratio in the surrounding soil is higher (larger

2 than 1) for equal strain which again confirms the fact that the external load is mostly

3 carried by the surrounding soil at the beginning (Figure 6b). However, the excess pore

4 pressure in the surrounding soil is lower for equal strain when T equals to 0.01 , which

5 means that equal strain induces faster consolidation. Figure 6 also demonstrates that

6 the excess pore pressure in the surrounding soil is not as sensitive to depth as it is in

7 stone column, possibly due to the ignorance of vertical flow in surrounding soil. Note

8 that the small variation with depth is attributed to the pore pressure gradient in stone

9 column.

\section{Effect of foundation stiffness}

11 In practice, the stiffness of a foundation is neither infinity nor zero, therefore, the

12 performance of soft ground improved by stone columns should be between equal strain

13 and free strain. By varying the stiffness of the foundation, this behaviour can be

14 captured by the proposed consolidation model. A parametric study was carried out to

15 investigate the effect of foundation stiffness on the stone column, and the same

16 parameters provided in Table 1 were used, except for the stiffness of foundation.

17 By considering the foundation layer as a common earth structure, the stiffness of the

18 foundation layer can be determined based on direct shear tests of its base soil, while 
1 the typical values of stiffness, $K$, can be calculated from the existing direct shear tests

2 that are listed in Table 2. As for a 2-3m high embankment, the lateral earth pressure is

3 limited, and therefore, the resulting $\mathrm{K}$ value is expected to be relatively low. In the

4 following analysis, the foundation stiffness was altered by using the compressibility of

5 the surrouding soil as a reference; the product of foundation stiffness and volume

6 compressibility $\left(\mathrm{K} \cdot \mathrm{m}_{\mathrm{vs}}\right)$ varies from 0.1 to 10 , which corresponds to a stiffness of 200

$7 \quad \mathrm{kPa}$ to $20,000 \mathrm{kPa}$.

8 Figure 7(a) shows that the change in foundation stiffness affects the consolidation rate.

9 Initially, the rate decreases as the foundation stiffness increases, but after a certain time

$10 \quad(\mathrm{~T} \approx 0.03)$ the consolidation accelerates when the foundation becomes stiffer, and cases

11 of equal strain and free strain become the upper and lower boundary.

12 Naturally, the stress concentration ratio on top of the unit cell is also influenced by the

13 stiffness of the foundation, as shown in Figure 7(b). The external loading is initially

14 carried by the surrounding soil, but as consolidation progresses it is gradually

15 transferred to the stone column. The stress concentration ratio approaches a steady

16 value when consolidation approaches to the end. The steady stress concentration ratio

17 increases as the foundation become stiffer, and in this case the steady stress

18 concentration ratio is 7 (corresponding to the equal strain condition). 
1 The differential settlement ratio $(\Delta S / H)$ is defined as the ratio of differential settlement

2 at the top of the unit cell to the height of the unit cell. Figure 7(c) shows that less

3 differential settlement is generated as the foundation becomes stiffer. For a flexible

4 foundation, negative differential settlement (around 2\%) develops initially which

5 means the column settles more than the surrounding soil at the beginning due to its high

6 permeability, but then this trend reverses until the differential settlement becomes

7 positive and finally reaches a steady value. This can be explained as follows: the excess

8 pore pressure in the surrounding soil takes much longer to dissipate than inside the

9 stone column, therefore, the compression of surrounding soil develops much slower

10 than that of stone column, and the surrounding soil settles more than the column

11 initially. Figure 7(c) also indicates that the differential settlement ratio can be negligible

12 when the foundation is stiff, but it could be up to $18 \%$ when the foundation is flexible.

13 Note that this amount of differential settlement is not realistic in field conditions

14 because of the resistance mobilised at the column-soil interface, but the results

15 presented hereby still highlight the need to evaluate the differential settlement.

16 Effect of modulus ratio, spacing ratio, and permeability ratio

17 The sensitivity of the modulus ratio, the permeability ratio of column material to soil,

18 and column spacing are also studied under conditions between equal strain and free

19 strain. Slightly different from the previous section, in this part, the stiffness of $22 / 56$ 
1 foundation is assigned as 1000,2000 and $4000 \mathrm{kPa}$, respectively (corresponds to the

$2 \mathrm{~K} \cdot \mathrm{m}_{\mathrm{vs}}$ values of $\left.0.5,1,2\right)$.

3 The quality (modulus) of stone column is crucial for the performance of the improved

4 soft ground (Deb and Behera, 2016; Raju and Sondermann, 2005). In practice, the

5 modulus ratio of column to clay is in the range of 10-40 ( Hu, 1995, Kelly, 2014). Based

6 on elastic theory, the coefficient of volume compressibility, $\mathrm{m}_{\mathrm{v}}$, can be calculated using

7 Poisson's ratio, $v$, and Young's modulus, $E_{0}$ from the equation given below (Han and

8 Ye, 2001).

$$
m_{v}=\frac{(1+v)(1-2 v)}{E_{0}(1-v)}
$$

9 Han and Ye (2001) also suggested that the Poisson's ratios for stone column and

10 surrounding soil should be chosen as 0.15 and 0.45 , respectively. As a result, the ratio

11 of coefficient of compressibility of clay to column is in the range of 2 to 11 when the

12 modulus ratio of column to clay varies between 8 and 40 .

13 The influence of modulus ratio under various values of foundation stiffness is

14 investigated and the corresponding results are shown in Figure 8. The steady stress

15 concentration ratio under different modulus ratios is compared to previous predictions

16 (Barksdale and Bachus, 1983, Han and Ye, 2001) in Figure 8(a), and it is observed that

17 these results follow a similar trend except that the current model shows slight 
1 nonlinearity. It is also noted that the steady stress concentration ratio increases with an

2 increase in either modulus ratio or foundation stiffness, but the effect of foundation

3 stiffness becomes negligible when the modulus ratio is relatively small (i.e. $<10$ ).

4 The time factor corresponding to $90 \%$ degree of consolidation, $\mathrm{U}_{90}$, is usually used as

5 an indicator to compare the consolidation rate among different cases. Figure $8(\mathrm{~b})$

6 illustrates that $\mathrm{U}_{90}$ decreases as the modulus ratio increases or the foundation becomes

7 stiffer. When the modulus ratio is less than 10 , the value of $U_{90}$ is not sensitive to the

8 foundation stiffness.

9 Note that the differential settlement ratio increases with an increase in the modulus

10 ratio, but it decreases as the foundation becomes stiffer, as shown in Figure 8(c). The

11 differential settlement is likely to be affected significantly by the stiffness of foundation

12 even at a relatively low modulus ratio (i.e. $<10)$. Similarly, the radius ratio of unit cell to

13 column $\left(\mathrm{r}_{\mathrm{s}} / \mathrm{r}_{\mathrm{c}}\right)$ and the permeability ratio of column material to clay $\left(\mathrm{k}_{\mathrm{c}} / \mathrm{k}_{\mathrm{s}}\right)$ are also

14 varied under different values of stiffness of foundation. The radius ratio changes in the

15 range of 1.5-3.5 while the permeability ratio varies between $10^{3}$ and $10^{6}$, both of which

16 are in the typical range $\left(\mathrm{Hu}, 1995 ;\right.$ Kelly, 2014). Only $\mathrm{U}_{90}$ is calculated to show the

17 change of consolidation rate, as the stress concentration and differential settlement are

18 unlikely to be affected significantly in this scenario. Figure 9 (a) shows that $U_{90}$ is

19 normally higher for a larger radius ratio, and its value also increases slightly as the 
1 foundation becomes stiffer under a certain radius ratio. Figure 9(b) illustrates that

2 further increase in the permeability ratio beyond $10^{4}$ barely accelerates consolidation

3 anymore, and $\mathrm{U}_{90}$ is not sensitive to the stiffness of the foundation at a given

4 permeability ratio.

\section{$5 \quad$ Practical design illustrative example}

6 An example is given to illustrate how this proposed model can be used for a practical

7 design. In a project where $0.8 \mathrm{~m}$ diameter stone columns are spaced $2 \mathrm{~m}$ apart in a

8 rectangular pattern are used to stabilise a 10-meter-thick layer of soft clay over an

9 impervious rock bed. Then it can be determined that the equivalent radius of the unit

10 cell is $2.26 \mathrm{~m}$, which is 1.13 times of the column spacing, and an annular area outside

11 the stone column with a diameter of $0.92 \mathrm{~m}$ is disturbed due to installation. The

12 permeability of undisturbed clay, disturbed clay, and column material are $10^{-9}, 10^{-10}$,

13 and $10^{-4} \mathrm{~m} / \mathrm{s}$, respectively. The coefficient of volume compressibility of column

14 material and clay are 0.08 and $0.8 \mathrm{MPa}^{-1}$, respectively. The stiffness of foundation is

$152,000 \mathrm{kPa}$. A $100 \mathrm{kPa}$ vertical load is applied instantly and the degree of consolidation

16 after 30 days and the time to achieve $90 \%$ of consolidation degree $\left(\mathrm{U}_{90}\right)$ are required.

17 The proposed model predicts that the degree of consolidation after 30 days is $53.2 \%$

18 and $U_{90}$ takes around 95 days. In comparison, the model of Han and Ye (2002) shows

19 that the degree of consolidation after 30 days is $66.5 \%$ and $\mathrm{U}_{90}$ is 63 days, whereas $\mathrm{Lu}$ $25 / 56$ 
1 et al. (2010)'s model predicts that the 30-day degree of consolidation is $60 \%$ and $\mathrm{U}_{90}$

2 can be achieved within 79 days.

\section{Application to a case study}

4 In mid-2012 at the Ballina national field test facility, NSW, Australia, a group of stone columns

5 were installed to improve the local soft clay. These fully-penetrated stone columns were in a

6 square pattern at a spacing of 2-metre. Subsequently a $4 \mathrm{~m}$ high embankment was built in four

7 stages within 50 days. The first metre of the embankment consisted of rockfill overlain with a

8 layer of geogrid; the natural unit weight of embankment fill was between $17.5-20 \mathrm{kN} / \mathrm{m}^{3}$ which

9 resulted in a vertical load of approximately $70-80 \mathrm{kPa}$. The properties of Ballina clay and

10 general site condition have been reported in detail elsewhere (Kelly et al., 2016; Pineda et al.,

11 2016) and are summarised in Table 3. The water table is close to the ground surface. This

12 layer of soft Ballina clay is around 10-13 metres thick and is underlain by mixture of sand and

13 stiff clay.

14 Figure 10 shows a cross section of this embankment. Several settlement plates and

15 earth pressure cells have been installed at the top surface of the central column.

16 Differential settlement was observed between the central column and the adjacent soil

17 surface while the stress concentration ratio was recorded by earth pressure data. The 
1 proposed model was used to make a prediction and the basic parameters are given in

2 Table 4.

3 A comparison between the measurements and model predictions are shown in Figure

4 11. Figure 11(a) shows that the prediction for the first 50 days agrees well with the

5 measurement; the proposed model can capture the differential settlement between

6 column surface $\left(\mathrm{S}_{\mathrm{c}}\right)$ and soil surface $\left(\mathrm{S}_{\mathrm{s}}\right)$ which is missing in equal strain analysis,

7 and the prediction is better when $\mathrm{K}$ is equal to $1000 \mathrm{kPa}$. The prediction under free

8 strain condition is not shown because there is inevitable redistribution of stress that

9 occurs at the top of the unit cell. As for the stress concentration ratio (Figure 11b), the

10 monitoring data were only available for the first 100 days because of the

11 malfunctioning sensor. The measured stress concentration ratio is in the range of 2 to

123 and has a slightly increasing trend. Although the model predicted a faster increase

13 and a higher steady value, it still provides a closer match compared to the equal strain

14 condition.Figure 11 Embankment at Ballina: (a) construction order and settlement; (b)

15 stress concentration ratio

16 Model limitation

17 Although the proposed model can provide solutions for the consolidation of soft ground

18 improved with stone column under equal strain, free strain, and conditions in-between, 
1 by considering the foundation stiffness, there are still some inevitable limitations listed

2 below, as also demonstrated through the case study.

3 (i) Shear stress would be expected at the rough column-soil interface, but complexities would arise due to the intrusion of fine particles into the

11 (iii) Vertical flow in the surrounding soil is ignored, which is acceptable for a the column the less), and this is not considered in the proposed model.

\section{Conclusions}

17 A new consolidation model was presented to capture the consolidation of soft ground

18 improved by stone columns under conditions ranging from equal strain to free strain 
1 by incorporating the stiffness of the foundation. The shear stress generated in the

2 foundation layer is determined using a method similar to Terzaghi's "trapdoor theory".

3 This method of stress redistribution is combined with consolidation to obtain

4 generalized closed-form solutions. The derived solution was validated by comparison

5 with previous models either under equal strain or free strain. The results showed that

6 for stone columns, the difference between those two situations were significant and the

7 consolidation curves corresponding to equal strain and free strain became the upper

8 and lower boundary, respectively. It is observed that consolidation under free strain

9 condition developed faster than equal strain initially, but then the trend reversed.

10 A parametric study was also carried out to examine and quantify the effect of

11 foundation stiffness; it showed that when the stiffness of the foundation increases, (a)

12 the time needed to achieve $90 \%$ of degree of consolidation decreases, (b) the steady

13 stress concentration ratio increases, and (c) the differential settlement at the ground

14 surface decreases. The influence of foundation stiffness under different modulus ratios

$15\left(\mathrm{E}_{\mathrm{c}} / \mathrm{E}_{\mathrm{s}}\right)$, radius ratios $\left(\mathrm{r}_{\mathrm{s}} / \mathrm{r}_{\mathrm{c}}\right)$, and permeability ratios $\left(\mathrm{k}_{\mathrm{c}} / \mathrm{k}_{\mathrm{s}}\right)$ was also evaluated in this

16 study. It was found that when the modulus ratio increases, consolidation becomes

17 more sensitive to variations in the foundation stiffness, however, the effect of

18 foundation stiffness on the consolidation rate is marginal under different radius ratios

19 and permeability ratios. 
1 An illustrative example is provided to demonstrate that the assumption of equal strain

2 may lead to an overestimation of the consolidation degree in practice. Moreover, a

3 case study at Ballina, NSW with detailed settlement and total stress measurements

4 was also presented and analysed using the proposed model. Besides the conventional

5 prediction of consolidation rate, additional features such as the differential settlement

6 and the stress concentration ratio at ground surface can also be well captured. Despite

7 of some deviation existing, it is still shown that this analytical model is capable of

8 giving more realistic results than that under equal strain condition.

\section{Acknowledgement}

10 The authors would like to thank the financial support from the Australian Research

11 Council (ARC) linkage project (LP130100839). The authors thank all the staff

12 involved in the field test and their support. The first author also appreciates the helpful

13 discussion with Dr. Rui Zhong.

\section{References}

15 Barron, R.A., 1948. Consolidation of Fine-Grained Soils by Drain Wells. Transactions of the 16 American Society of Civil Engineers, 113(1): 718-742.

17 Bouassida, M. and Carter, J.P., 2014. Optimization of Design of Column-Reinforced 18 Foundations. International Journal of Geomechanics: 04014031.

19 Chen, R., Chen, Y., Han, J. and Xu, Z., 2008. A theoretical solution for pile-supported 20 embankments on soft soils under one-dimensional compression. Canadian 21 Geotechnical Journal, 45(5): 611-623. 
Dafalla, M.A., 2013. Effects of clay and moisture content on direct shear tests for clay-sand mixtures. Advances in Materials Science and Engineering, 2013: 1-8.

Deb, K. and Behera, A., 2016. Rate of consolidation of stone column-improved ground considering variable permeability and compressibility in smear zone. International Journal of Geomechanics, 17(6): 04016128.

Han, J., 2014. Recent research and development of ground column technologies, Proceedings of the Institution of Civil Engineers-Ground Improvement, pp. 246-264.

Han, J. and Ye, S.L., 2001. Simplified Method for Consolidation Rate of Stone Column Reinforced Foundations. Journal of Geotechnical and Geoenvironmental Engineering, 127(7): 597-603.

Hansbo, S., Jamiolkowski, M. and Kok, L., 1981. Consolidation by vertical drains. Géotechnique, 31(1): 45-66.

Hu, W., 1995. Physical modelling of group behaviour of stone column foundations. Doctoral Thesis, University of Glasgow.

Indraratna, B., Basack, S. and Rujikiatkamjorn, C., 2013. Numerical Solution of Stone Column-Improved Soft Soil Considering Arching, Clogging, and Smear Effects. Journal of Geotechnical and Geoenvironmental Engineering, 139(3): 377-394.

Ishibashi, I., 2011. Soil mechanics fundamentals. Boca Raton, FL : CRC Press, Boca Raton, FL.

Jewell, R.A., 1989. Direct shear tests on sand. Géotechnique, 39(2): 309-322.

Kelly, P., 2014. Soil Structure Interaction and Group Mechanics of Vibrated Stone Column Foundations. Doctoral Thesis, University of Sheffield.

Kelly, R.B., Pineda, J., Bates, L., Suwal, L. and Fitzallen, A., 2016. Site characterisation for the Ballina field testing facility. Géotechnique, 67(4): 279-300.

Kreyszig, E., 1988. Advanced engineering mathematics. New York : Wiley, New York.

Lei, G., Zheng, Q., Ng, C., Chiu, A. and Xu, B., 2015. An analytical solution for consolidation with vertical drains under multi-ramp loading. Géotechnique, 65(7): 531-547.

Leo, C.J., 2004. Equal strain consolidation by vertical drains. Journal of Geotechnical and Geoenvironmental engineering, 130(3): 316-327.

Low, B., Tang, S. and Choa, V., 1994. Arching in piled embankments. Journal of Geotechnical Engineering, 120(11): 1917-1938.

Lu, M.M., Xie, K.H. and Guo, B., 2010. Consolidation theory for a composite foundation considering radial and vertical flows within the column and the variation of soil permeability within the disturbed soil zone. Canadian Geotechnical Journal, 47(2): 207-217.

Madhav, M. and Van Impe, W., 1994. Load transfer through a gravel bed on stone column reinforced soil. Geotechnical Engineering, 25(2): 47-62. 
1 Morgenstern, N. and Tchalenko, J., 1967. Microscopic structures in kaolin subjected to direct shear. Geotechnique, 17(4): 309-328.

3 Pineda, J., Suwal, L., Kelly, R., Bates, L. and Sloan, S., 2016. Characterisation of Ballina clay. Géotechnique, 66(7): 556-577.

Raju, V.R. and Sondermann, W., 2005. Chapter 21 Ground improvement using deep vibro techniques. In: B. Indraratna and J. Chu (Editors), Elsevier Geo-Engineering Book Series. Elsevier, pp. 601-638.

Richart, F.E., 1959. Review of the theories for sand drains. Transactions of the American Society of Civil Engineers, 124(1): 709-736.

Rujikiatkamjorn, C. and Indraratna, B., 2014. Analytical Solution for Radial Consolidation Considering Soil Structure Characteristics. Canadian Geotechnical Journal, 52(7): 947-960.

Schofield, A. and Wroth, P., 1968. Critical state soil mechanics, 310. McGraw-Hill London.

Simoni, A. and Houlsby, G.T., 2006. The direct shear strength and dilatancy of sand-gravel mixtures. Geotechnical \& Geological Engineering, 24(3): 523.

Tai, P., Indraratna, B. and Rujikiatkamjorn, C., 2017. Experimental simulation and mathematical modelling of clogging in stone column. Canadian Geotechnical Journal, 55(3): 427-436.

Tang, X.W. and Onitsuka, K., 1998. Consolidation of ground with partially penetrated vertical drains. Geotechnical Engineering Journal, 29(2): 209-231.

Terzaghi, K., 1943. Theoretical soil mechanics. Wiley, New York.

Tien, H.J., 1996. A literature study of the arching effects, Massachusetts Institute of Technology.

Van Eekelen, S., Bezuijen, A. and Van Tol, A., 2013. An analytical model for arching in piled embankments. Geotextiles and Geomembranes, 39: 78-102.

Walker, R. and Indraratna, B., 2006. Vertical drain consolidation with parabolic distribution of permeability in smear zone. Journal of Geotechnical and Geoenvironmental Engineering, 132(7): 937-941.

Wang, G., 2009. Consolidation of Soft Clay Foundations Reinforced by Stone Columns under Time-Dependent Loadings. Journal of Geotechnical and Geoenvironmental engineering, 135(12): 1922-1931.

Xie, K.H., Lu, M.M. and Liu, G.B., 2009. Equal strain consolidation for stone columns reinforced foundation. International Journal for Numerical and Analytical Methods in Geomechanics, 33(15): 1721-1735.

$\mathrm{Xu}, \mathrm{W} ., \mathrm{Xu}, \mathrm{Q}$. and Hu, R., 2011. Study on the shear strength of soil-rock mixture by large scale direct shear test. International Journal of Rock Mechanics and Mining Sciences, 48(8): 1235-1247. 
1 Zhu, G. and Yin, J.H., 2001. Consolidation of soil with vertical and horizontal drainage under ramp load. Géotechnique, 51(4): 361-367.

3 Zhu, G. and Yin, J.H., 2004. Accuracy of Carrillo's formula for consolidation of soil with 4 vertical and horizontal drainage under time-dependent loading. Communications in numerical methods in engineering, 20(9): 721-735.

6 


\section{Appendix I: derivation of Eqn. (6) and (7)}

2 Combing Eqn. (3) and (4) together would yield:

$$
\Delta \sigma=-\frac{r_{c}\left(r_{c}^{2}-r_{s}^{2}\right)\left(\sigma_{c}-\sigma_{s}\right)}{H_{1} r_{s}^{2}}
$$

3 Substitute (a1) into (5),

$$
\int_{0}^{H}\left(\varepsilon_{s}-\varepsilon_{c}\right) d z=-\frac{r_{c}\left(r_{c}^{2}-r_{s}^{2}\right)\left(\sigma_{c}-\sigma_{s}\right)}{K r_{s}^{2}}
$$

4 Because the stress items are independent of depth, therefore, the right side of Eqn. (a2)

5 can be rewritten as:

$$
-\frac{r_{c}\left(r_{c}^{2}-r_{s}^{2}\right)\left(\sigma_{c}-\sigma_{s}\right)}{K r_{s}^{2}}=-\int_{0}^{H} \frac{r_{c}\left(r_{c}^{2}-r_{s}^{2}\right)\left(\sigma_{c}-\sigma_{s}\right)}{H K r_{s}^{2}} d z
$$

6 Then Eqn. (a2) becomes an integral equation:

$$
\int_{0}^{H}\left[\left(\varepsilon_{s}-\varepsilon_{c}\right)+\frac{r_{c}\left(r_{c}^{2}-r_{s}^{2}\right)\left(\sigma_{c}-\sigma_{s}\right)}{H K r_{s}^{2}}\right] d z=0
$$

7 The integral equation usually does not have a general solving procedure, but a

8 solution can be easily speculated.

$$
\left(\varepsilon_{s}-\varepsilon_{c}\right)+\frac{r_{c}\left(r_{c}^{2}-r_{s}^{2}\right)\left(\sigma_{c}-\sigma_{s}\right)}{H K r_{s}^{2}}=0
$$

9 Combining (a5) and (a1) gives:

$$
\Delta \sigma=\frac{H K}{H_{1}}\left(\varepsilon_{s}-\varepsilon_{c}\right)
$$

10 Substituting Eqn. (a6) into Eqns. (3) and (4) would yield: 


$$
\begin{gathered}
\sigma_{s}=\sigma+\frac{K r_{c} H\left(\varepsilon_{s}-\varepsilon_{c}\right)}{r_{c}^{2}-r_{s}^{2}} \\
\sigma_{c}=\sigma+\frac{K H\left(\varepsilon_{s}-\varepsilon_{c}\right)}{r_{c}}
\end{gathered}
$$

1 Take derivative of (a7) and (a8) with respect to time, $t$, and combining with Eqn. (1)

2 leads to:

$$
\begin{gathered}
\frac{\partial \varepsilon_{s}}{\partial t}=\frac{m_{v s}\left[H K r_{c} \frac{\partial \varepsilon_{c}}{\partial t}+\frac{\partial \bar{u}_{s}}{\partial t}\left(r_{c}^{2}-r_{s}^{2}\right)\right]}{m_{v s} H K r_{c}-r_{c}^{2}+r_{s}^{2}} \\
\frac{\partial \varepsilon_{c}}{\partial t}=\frac{m_{v c}\left(H K \frac{\partial \varepsilon_{s}}{\partial t}-\frac{\partial \bar{u}_{c}}{\partial t} r_{c}\right)}{m_{v c} H K+r_{c}}
\end{gathered}
$$

3 Combining (a9) and (a10), then Eqn. (6) and (7) can be obtained.

4 


\section{Appendix II: derivation of Eqn. (15)}

2 Integrating Eqn. (8) considering the radius from $r$ to $r_{s}$, and then combining Eqn. (10)

3 yields:

$$
\frac{\partial u_{s}}{\partial r}=\frac{\gamma_{w}\left(r_{s}^{2}-r^{2}\right)}{2 k_{s} f(r) r} \frac{\partial \varepsilon_{s}}{\partial t}
$$

4 Substituting (b1) into (9) gives:

$$
\frac{r_{s}^{2}-r_{c}^{2}}{r_{c}^{2}} \frac{\partial \varepsilon_{s}}{\partial t}+\frac{k_{c}}{\gamma_{w}} \frac{\partial^{2} \bar{u}_{c}}{\partial z^{2}}=-\frac{\partial \varepsilon_{c}}{\partial t}
$$

5 Integrating (b1), the following equation can be derived by incorporating (11), thus,

$$
u_{s}-\bar{u}_{c}=\frac{\gamma_{w}}{2 k_{s}} \frac{\partial \varepsilon_{s}}{\partial t} \int_{r_{c}}^{r} \frac{r_{s}^{2}-r^{2}}{f(r) r} d r
$$

6 A relationship can also be established between the average pore water pressure in the

7 surrounding clay and the pore pressure in the stone column, as given in (b4) and (b5).

$$
\begin{gathered}
\bar{u}_{s}=\frac{1}{\pi\left(r_{s}^{2}-r_{c}^{2}\right)} \int_{r_{c}}^{r_{s}} 2 \pi r u_{s} d r=\bar{u}_{c}+\frac{\gamma_{w} A}{k_{s}\left(r_{s}^{2}-r_{c}^{2}\right)} \frac{\partial \varepsilon_{s}}{\partial t} \\
A=\int_{r_{c}}^{r_{s}} r \int_{r_{c}}^{r} \frac{r_{s}^{2}-r^{2}}{f(r) r} d r d r
\end{gathered}
$$

8 Combining (6) with (b4) and (b5) gives:

$$
\begin{gathered}
\bar{u}_{s}=\bar{u}_{c}+B \frac{\partial \bar{u}_{c}}{\partial t}+C \frac{\partial \bar{u}_{s}}{\partial t} \\
B=-\frac{m_{v c} m_{v s} A K H r_{c}^{2} \gamma_{w}}{k_{S}\left(r_{c}^{2}-r_{s}^{2}\right)\left[K m_{v c} H\left(r_{c}^{2}-r_{s}^{2}\right)+r_{c}\left(r_{c}^{2}-r_{s}^{2}\right)-K H r_{c} m_{v s}\right]}
\end{gathered}
$$




$$
C=-\frac{A\left(K H m_{v c} m_{v s}+m_{v s} r_{c}\right) \gamma_{w}}{k_{s}\left[K m_{v c} H\left(r_{s}^{2}-r_{c}^{2}\right)+m_{v s} K H r_{c}^{2}+r_{c}\left(r_{s}^{2}-r_{c}^{2}\right)\right]}
$$

1 Then substituting (6) and (7) into (b2) gives:

$$
\begin{gathered}
\frac{\partial \bar{u}_{s}}{\partial t}=D \frac{\partial \bar{u}_{c}}{\partial t}+E \frac{\partial^{2} \bar{u}_{c}}{\partial z^{2}} \\
D=\frac{r_{c}^{2}\left[m_{v c} r_{c}\left(r_{c}^{2}-r_{s}^{2}\right)-m_{v c} m_{v s} K H r_{s}^{2}\right]}{\left(r_{c}^{2}-r_{s}^{2}\right)\left[m_{v s} r_{c}\left(r_{c}^{2}-r_{s}^{2}\right)-m_{v c} m_{v s} K H r_{s}^{2}\right]} \\
E=-\frac{k_{c} r_{c}^{2}\left[K m_{v c} H\left(r_{c}^{2}-r_{s}^{2}\right)+r_{c}\left(r_{s}^{2}-r_{c}^{2}\right)-m_{v s} K H r_{c}^{2}\right]}{\gamma_{w}\left(r_{c}^{2}-r_{s}^{2}\right)\left[m_{v s} r_{c}\left(r_{c}^{2}-r_{s}^{2}\right)-m_{v c} m_{v s} K H r_{s}^{2}\right]}
\end{gathered}
$$

2 Substituting (b9) into (b6) leads to:

$$
\bar{u}_{s}=\bar{u}_{c}+(B+C D) \frac{\partial \bar{u}_{c}}{\partial t}+C E \frac{\partial^{2} \bar{u}_{c}}{\partial z^{2}}
$$

3 Taking the derivative of Eqn. (b12) with respect to time, and then combining with

4 Eqn. (b9) to eliminate the item involving $\bar{u}_{s}$, allows one to obtain the governing 5 equation (15).

6 
$1 \quad$ List of Tables

2 Table 1 Parameters used for comparison with existing models

3 Table 2 Foundation stiffness for different geo-materials based on direct shear tests

4 Table 3 Properties of Ballina clay (Pineda et al. 2016)

5 Table 4 Parameters used in prediction of field embankment

6 
Table 1 Basic parameters used in analysis (Indraratna et al. 2013)

\begin{tabular}{ccccc}
\hline $\mathbf{k}_{\mathbf{s}}(\mathbf{m} / \mathbf{s})$ & $\mathbf{k}_{\mathrm{c}} / \mathbf{k}_{\mathbf{s}}$ & $\mathbf{r}_{\mathrm{c}}(\mathbf{m})$ & $\mathbf{r}_{\mathbf{s}}(\mathbf{m})$ & $\mathbf{r}_{\mathrm{d}} / \mathbf{r}_{\mathbf{c}}$ \\
\hline $1.6 \times 10^{-9}$ & $10^{3}$ & 0.5 & 1.5 & 1.15 \\
\hline $\mathbf{k}_{\mathrm{d}} / \mathbf{k}_{\mathbf{s}}$ & $\mathbf{M}\left(\mathbf{m}_{\mathrm{vs}} / \mathbf{m}_{\mathrm{vc}}\right)$ & $\mathbf{Y}_{\mathbf{w}}\left(\mathbf{k N} / \mathbf{m}^{3}\right)$ & $\mathbf{H}(\mathbf{m})$ & $\mathbf{m}_{\mathrm{vs}}\left(\mathbf{M P a}^{-1}\right)$ \\
\hline 0.1 & 7 & 10 & 16 & 2 \\
\hline
\end{tabular}

2

3 
1 Table 2 Foundation stiffness for different geo-materials based on direct shear tests

\begin{tabular}{cccccc}
\hline Sources & Soil Type & $\begin{array}{c}\text { Shear } \\
\text { rate }(\mathbf{m m} / \mathbf{s})\end{array}$ & $\begin{array}{c}\text { Specimen } \\
\text { dimension(mm) }\end{array}$ & $\begin{array}{c}\text { Normal } \\
\text { stress } \\
(\mathbf{k P a})\end{array}$ & $\begin{array}{c}\text { Corresponding } \\
\mathbf{K}^{*}(\mathbf{k P a})\end{array}$ \\
\hline Xu et al. (2011) & $\begin{array}{c}\text { Soil-rock } \\
\text { mixture }\end{array}$ & $0.1-0.133$ & $600 \times 600 \times 400$ & $10-40$ & $400-3000$ \\
\hline Dafalla (2013) & $\begin{array}{c}\text { Clay-sand } \\
\text { mixture }\end{array}$ & 0.002 & $100 \times 100$ & $49-147$ & $3000-10000$ \\
\hline $\begin{array}{c}\text { Simoni and } \\
\text { Houlsby (2006) }\end{array}$ & $\begin{array}{c}\text { Sand-gravel } \\
\text { mixture }\end{array}$ & 0.0056 & $254 \times 152 \times 150$ & 90 & $1000-5000$ \\
\hline $\begin{array}{c}\text { Jewell (1989) } \\
\text { Morgenstern } \\
\text { and Tchalenko } \\
\text { (1967) }\end{array}$ & Sand & - & $250 \times 152 \times 152$ & $30-33$ & $4000-11000$ \\
\hline
\end{tabular}

2 *Estimated based on the shear stress-horizontal displacement curves in the literature 3 


\begin{tabular}{|c|c|c|}
\hline Borehole number & Inclo2 & Mex9 \\
\hline Depth & $2.1 \mathrm{~m}-10.5 \mathrm{~m}$ & $2.8 m-10 m$ \\
\hline Water content & $78 \%-122 \%$ & $81 \%-113 \%$ \\
\hline Liquid limit & $87 \%-128 \%$ & $87 \%-127 \%$ \\
\hline Plastic limit & $32 \%-50 \%$ & $34 \%-46 \%$ \\
\hline Initial void ratio $e_{0}$ & 2.03-3.31 & $2.16-2.89$ \\
\hline Dry density $\rho_{d}\left(\mathrm{~g} / \mathrm{cm}^{3}\right)$ & $0.62-0.89$ & $0.65-0.87$ \\
\hline Coefficient of consolidation $c_{v}\left(\mathrm{~m}^{2} /\right.$ year $)$ & $2.5-285.9$ & $4.75-23.5$ \\
\hline Undrained shear strength $s_{u}(\mathrm{kPa})$ & $11-24$ & $10-26$ \\
\hline Permeability $k\left(10^{-9} \mathrm{~m} / \mathrm{s}\right)$ & $0.65-54$ & $0.5-4.7$ \\
\hline Modulus $M(\mathrm{kPa})$ & $1140-2561$ & $1587-3120$ \\
\hline
\end{tabular}


Table 4 Parameters used in prediction of field embankment

\begin{tabular}{ccccc}
\hline $\mathbf{H}(\mathrm{m})$ & $\mathbf{r}_{\mathrm{s}}(\mathrm{m})$ & $\mathbf{r}_{\mathrm{c}}(\mathbf{m})$ & $\mathbf{r}_{\mathrm{d}} / \mathbf{r}_{\mathrm{c}}$ & $\mathrm{K}(\mathbf{k P a})$ \\
\hline 10 & 1.13 & 0.4 & $\mathrm{~b} 1.15$ & $\mathrm{c} 500 / 1000$ \\
\hline $\mathbf{k}_{\mathbf{s}}(\mathrm{m} / \mathbf{s})$ & $\mathbf{k}_{\mathrm{c}}(\mathbf{m} / \mathbf{s})$ & $\mathbf{k}_{\mathrm{d}} / \mathbf{k}_{\mathbf{s}}$ & $\mathbf{m}_{\mathrm{vs}} / \mathbf{m}_{\mathrm{vc}}$ & $\mathbf{m}_{\mathrm{vs}}\left(\mathbf{M P a}^{-1}\right)$ \\
\hline $\mathrm{a} 10^{-9}$ & $\mathrm{~b} 10^{-4}$ & $\mathrm{~b} 0.1$ & $\mathrm{~b} 10$ & $\mathrm{a} 0.7$ \\
\hline
\end{tabular}

a. based on results of Pineda et al. (2016) and Kelly et al. (2017)

3 b. according to Han and Ye (2001), Indraratna et al. (2013)

4 c. Assumed based on Table 2

5 
$1 \quad$ List of Figures

2 Figure 1 A stone column unit cell

3 Figure 2 Shear stress in the foundation layer (a) trapdoor theory (Terzaghi 1943); (b)

4 typical stress-strain relationship (based on direct shear test)

$5 \quad$ Figure 3 Comparison between proposed model and previous models

6 Figure 4 Vertical stress on top of the unit cell: (a) vertical stress ratio; (b) stress

7 concentration ratio

8 Figure 5 Development of excess pore pressure for equal strain and free strain (depth of

$9 \quad 1 \mathrm{~m}$ and $10 \mathrm{~m}$ ): (a) surrounding soil; (b) stone column

10 Figure 6 Excess pore pressure profiles: (a) in stone column; (b) in surrounding soil

11 Figure 7 Effect of foundation stiffness on: (a) average degree of consolidation; (b)

12 stress concentration ratio; (c) differential settlement

13 Figure 8 Effect of modulus ratio under varying foundation stiffness: (a) steady stress

14 concentration ratio $\left(\mathrm{n}_{\mathrm{s}}\right)$; (b) time to achieve $90 \%$ degree of consolidation $\left(\mathrm{U}_{90}\right)$; (c)

15 differential settlement $\operatorname{ratio}(\Delta \mathrm{S} / \mathrm{H})$

16 Figure 9 Effect of foundation stiffness on U90: (a) radius ratio $\left(\mathrm{r}_{\mathrm{s}} / \mathrm{r}_{\mathrm{c}}\right)$; (b) permeability

17 ratio $\left(\mathrm{k}_{\mathrm{c}} / \mathrm{k}_{\mathrm{s}}\right)$

18 Figure 10 Cross-section of embankment beyond stone columns

19 Figure 11 Embankment at Ballina: (a) construction order and settlement; (b) stress

20 concentration ratio 


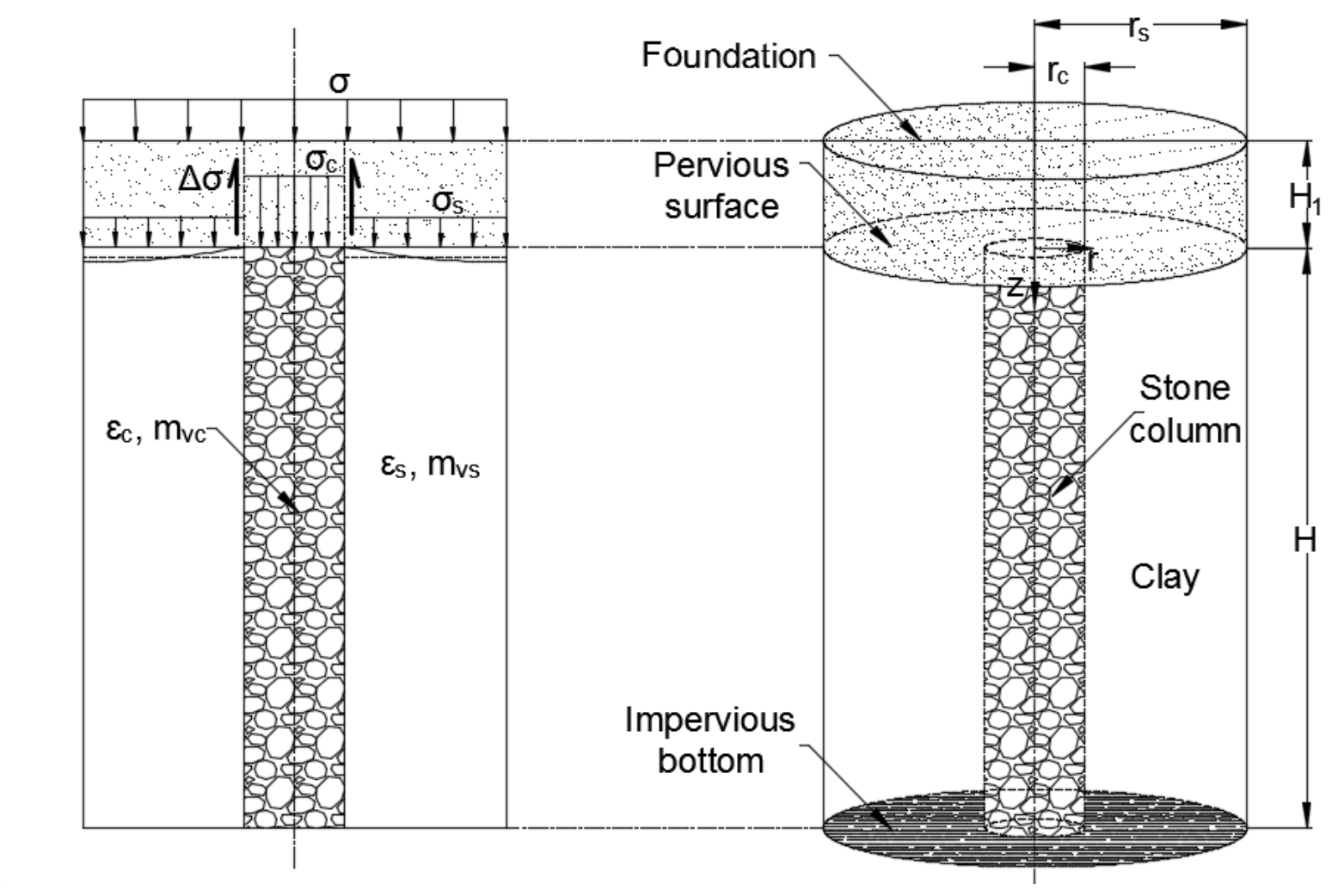

Figure 1 A stone column unit cell 


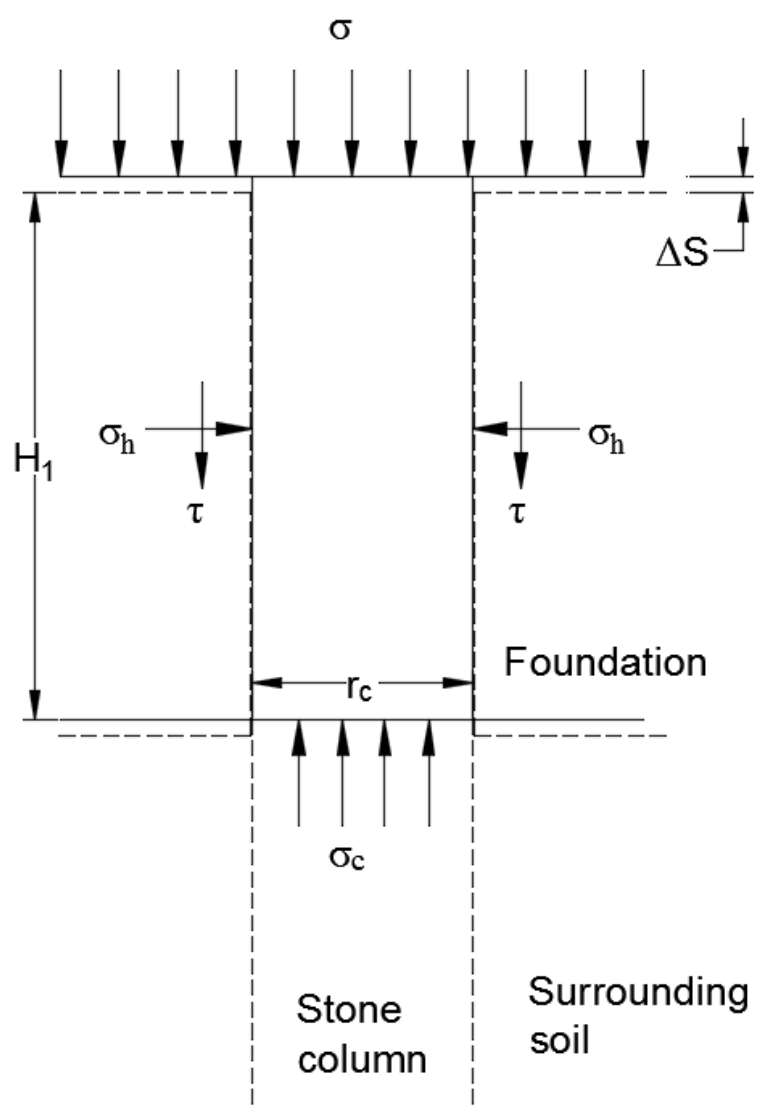

(a)

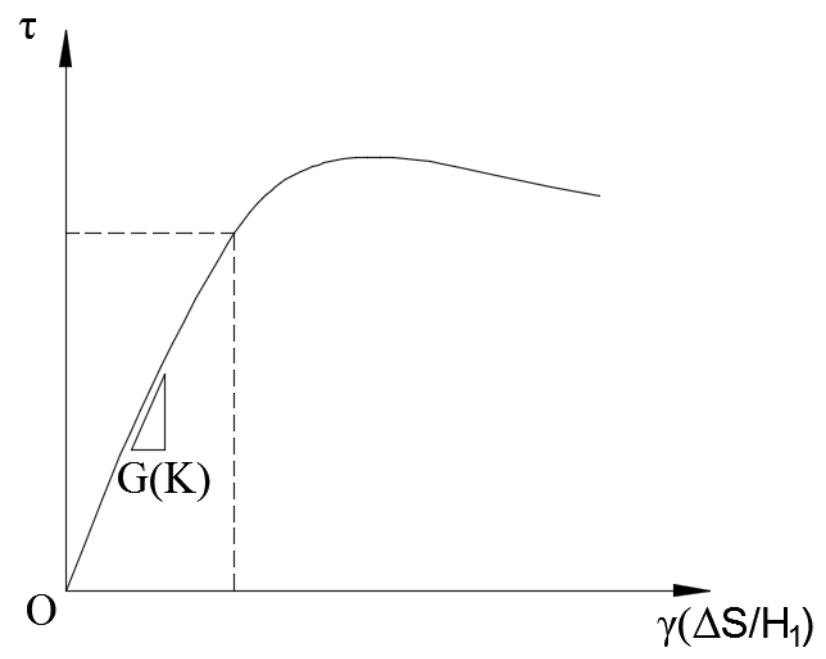

(b)

$5 \quad$ Figure 2 Shear stress in the foundation layer (a) trapdoor theory (Terzaghi 1943); (b) 6 typical stress-strain relationship (based on direct shear test) 


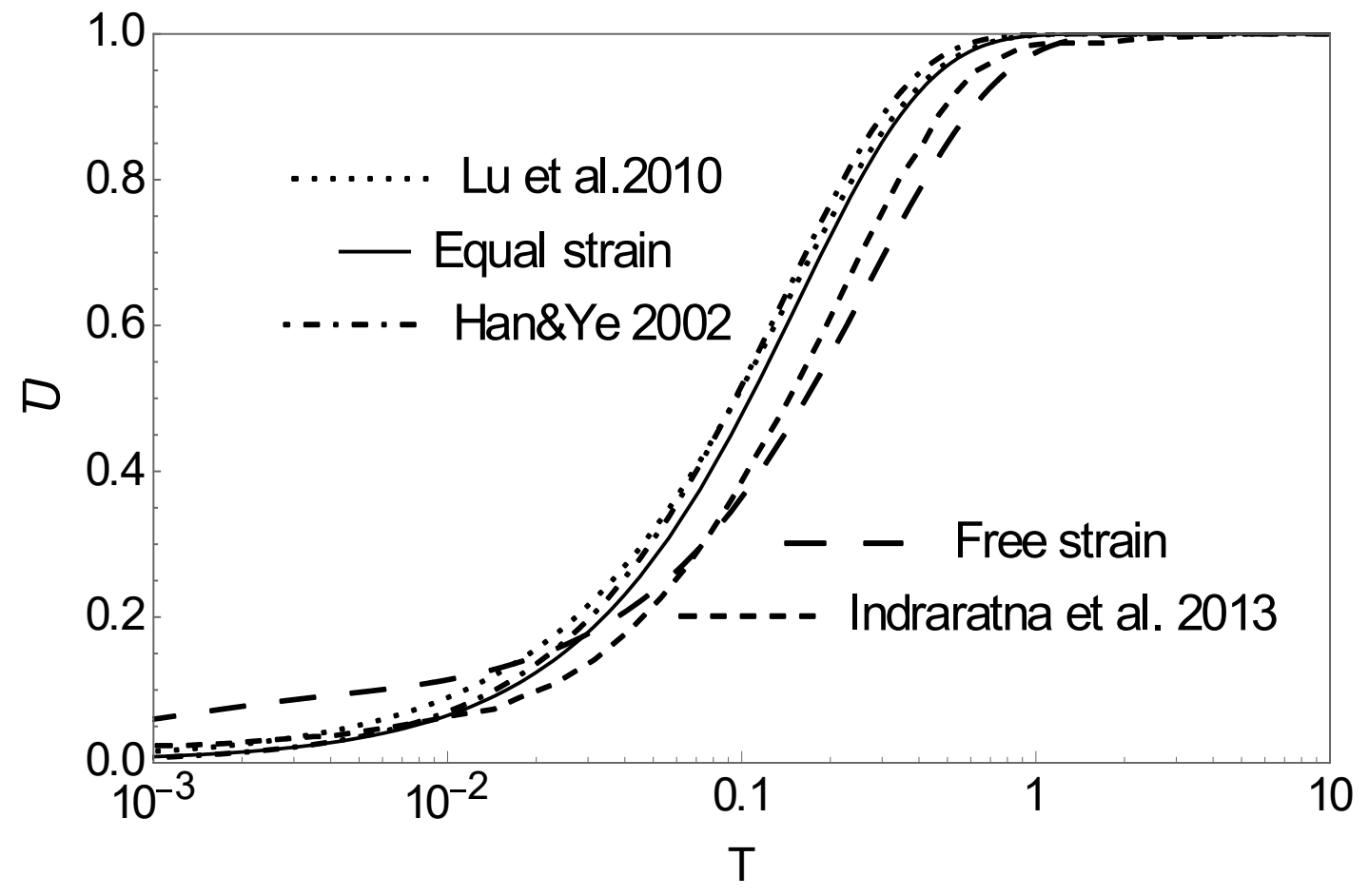

Figure 3 Comparison between proposed model and previous models 


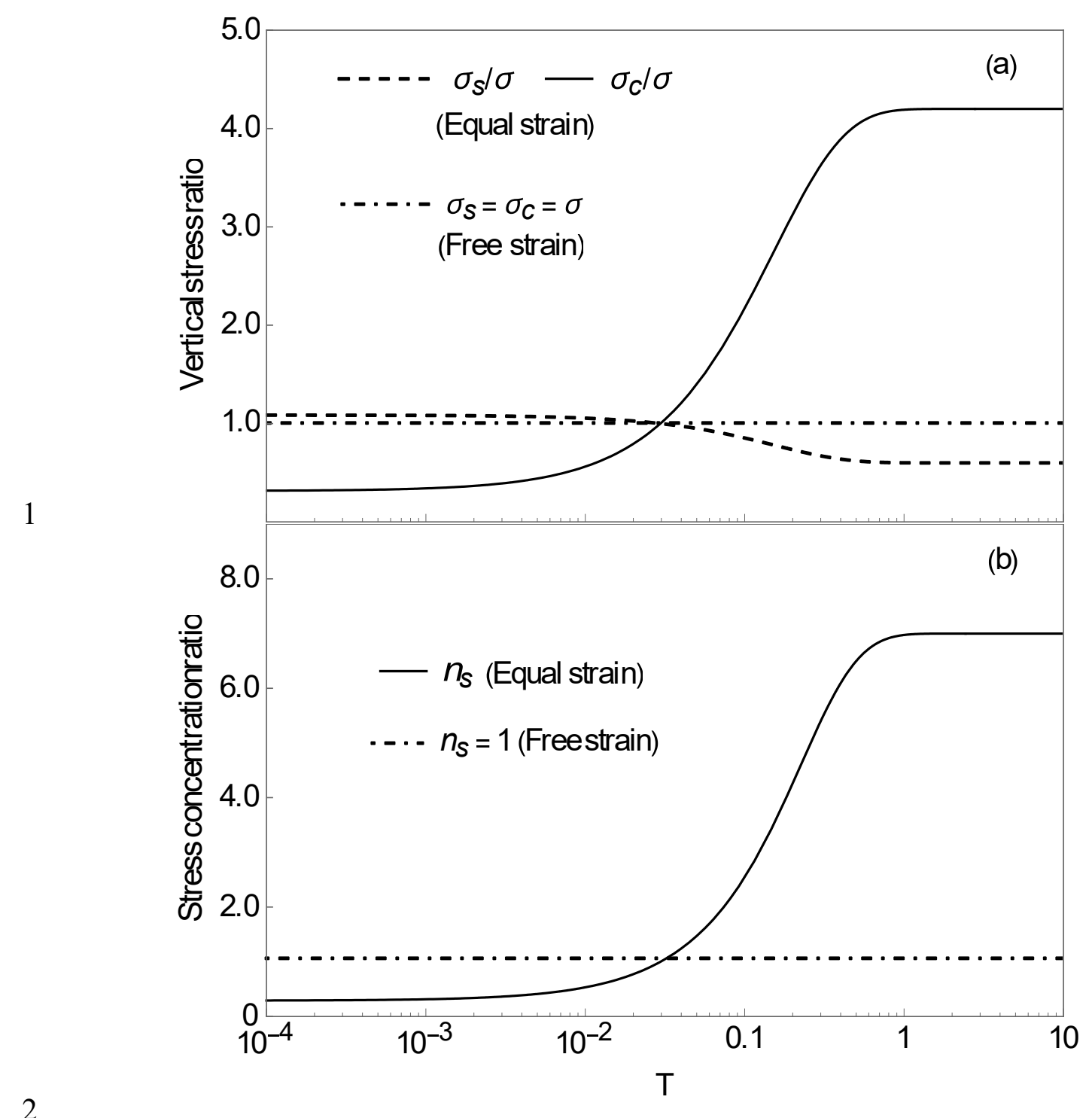

Figure 4 Vertical stress on top of the unit cell: (a) vertical stress ratio; (b) stress 4 concentration ratio 


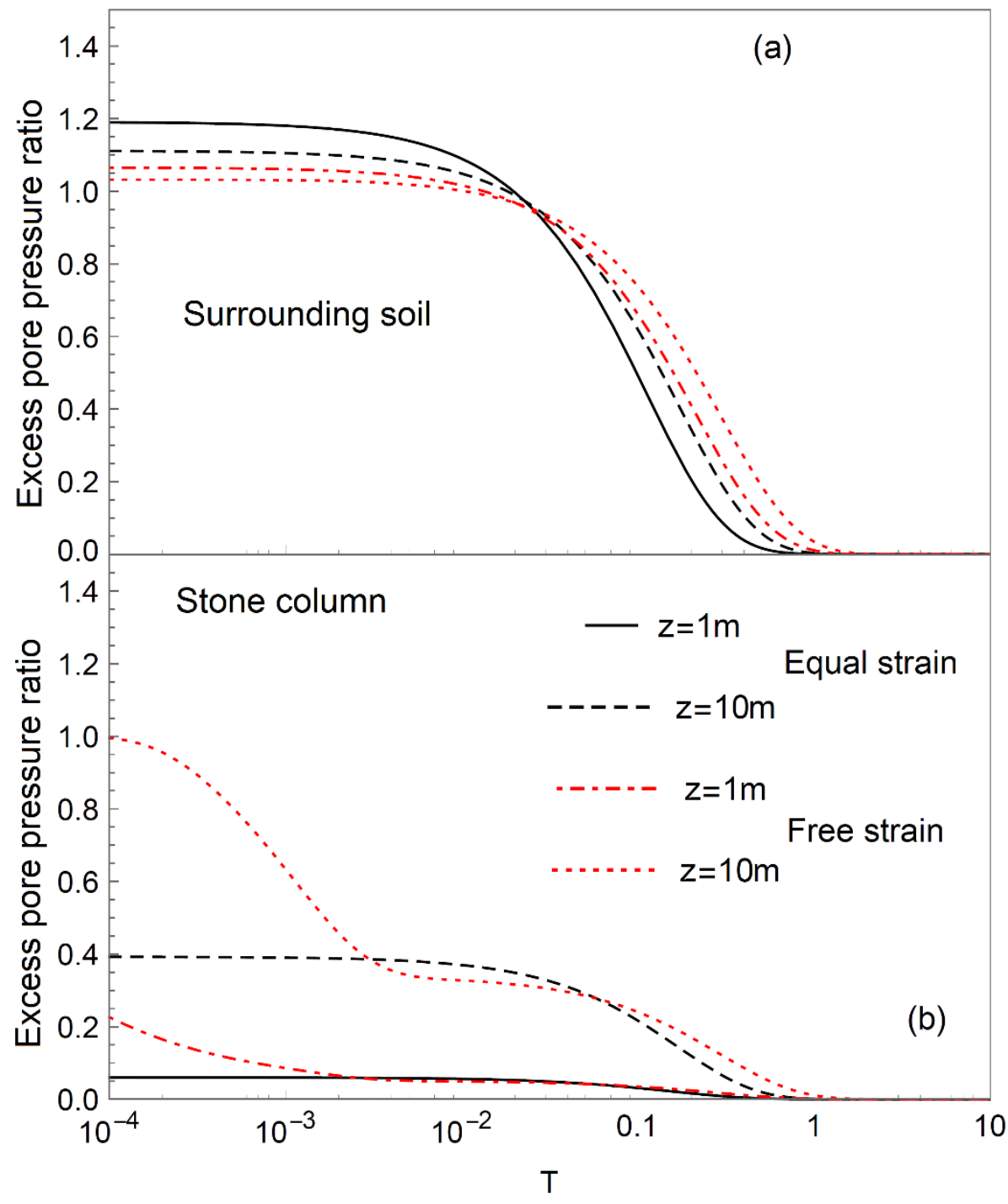

2 Figure 5 Development of excess pore pressure for equal strain and free strain (depth of 3 $1 \mathrm{~m}$ and 10m): (a) surrounding soil; (b) stone column 


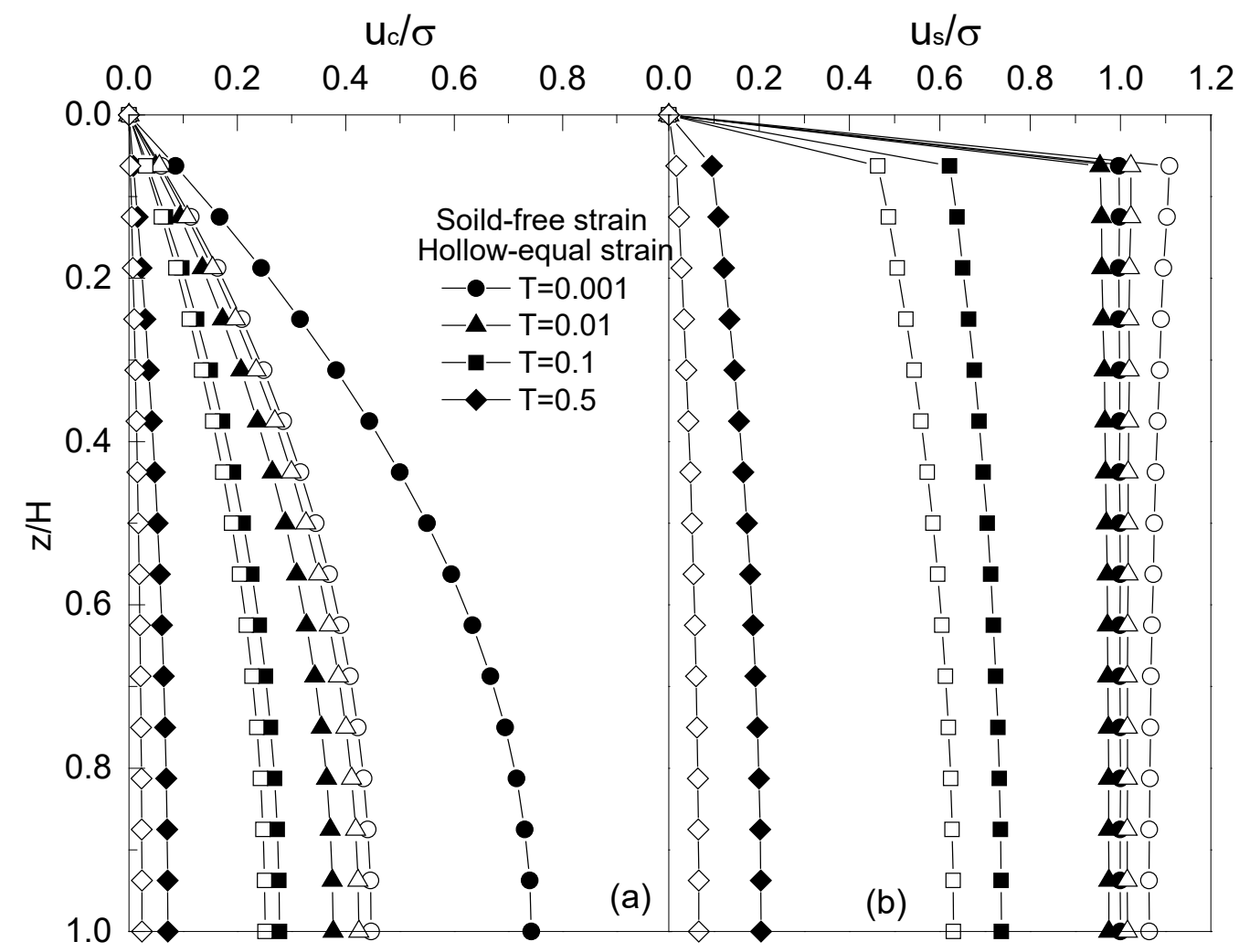

2 Figure 6 Excess pore pressure profiles: (a) in stone column; (b) in surrounding soil 3 


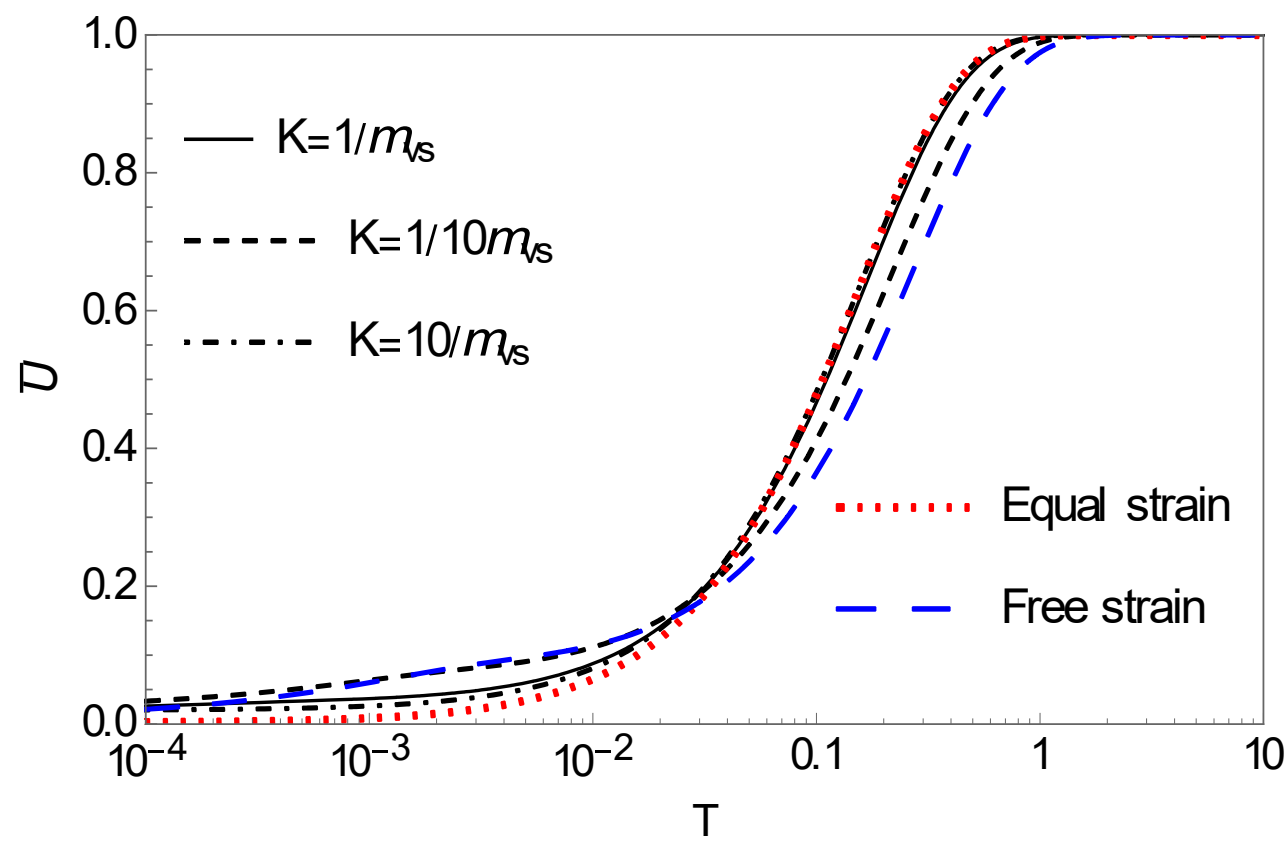

2

(a)

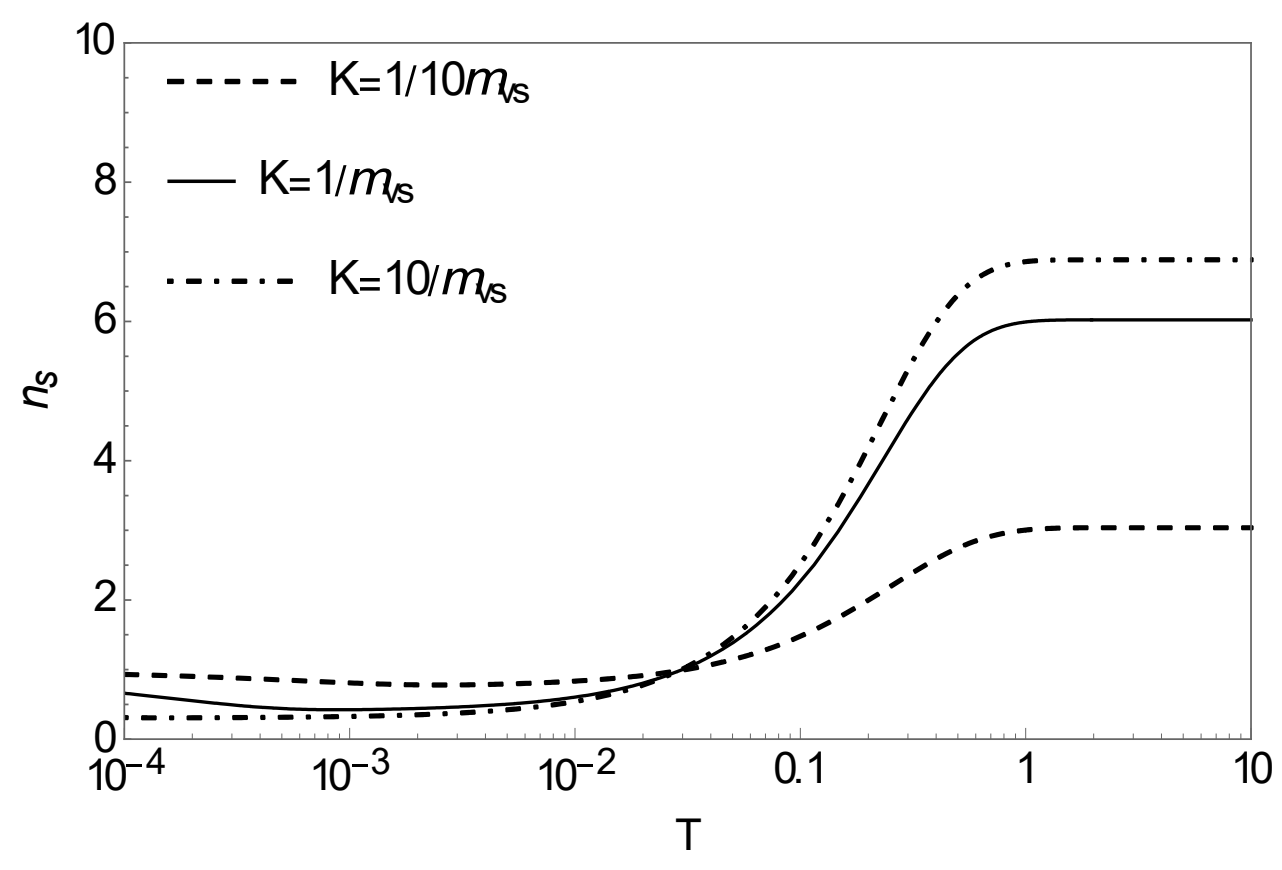

4

(b) 


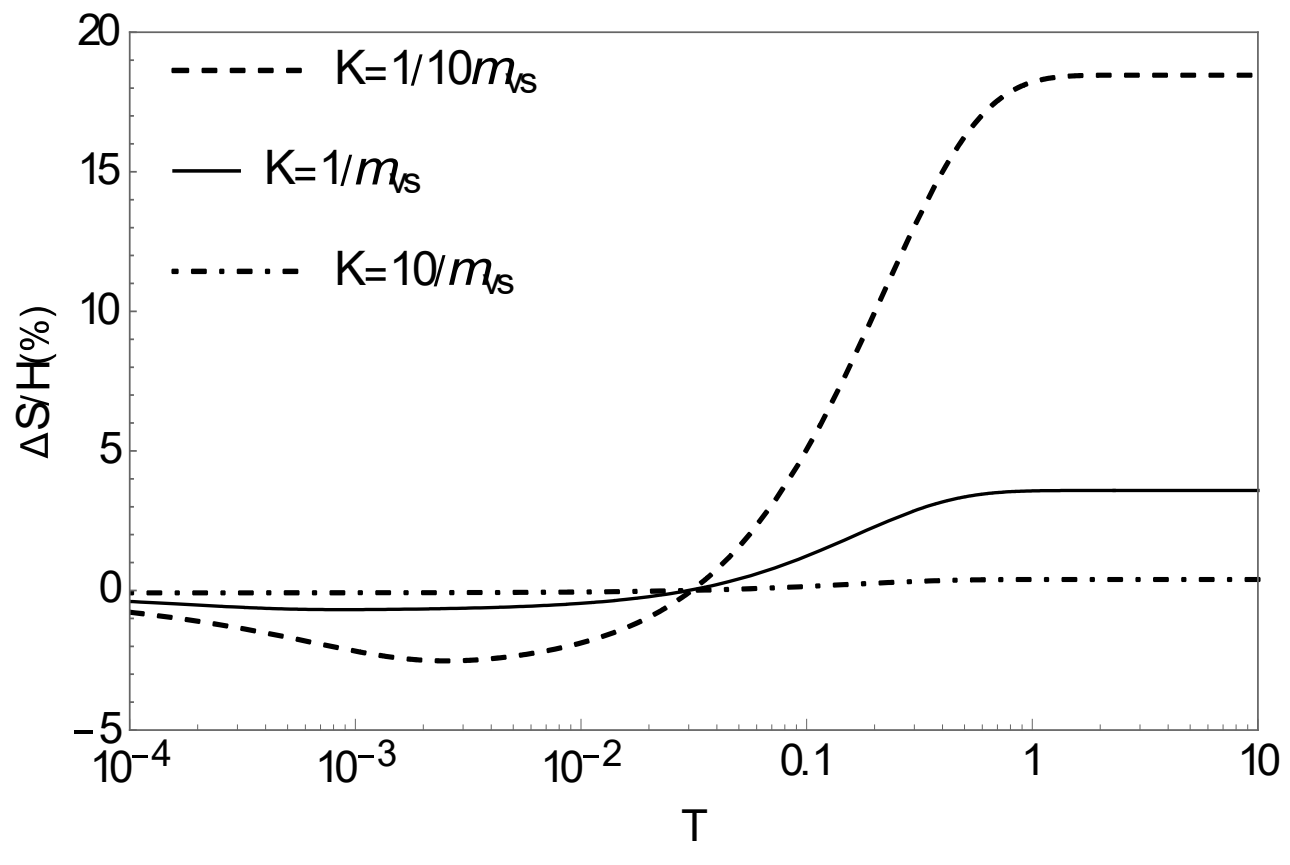

2

(c)

3 Figure 7 Effect of foundation stiffness on: (a) average degree of consolidation; (b) stress concentration ratio; (c) differential settlement 


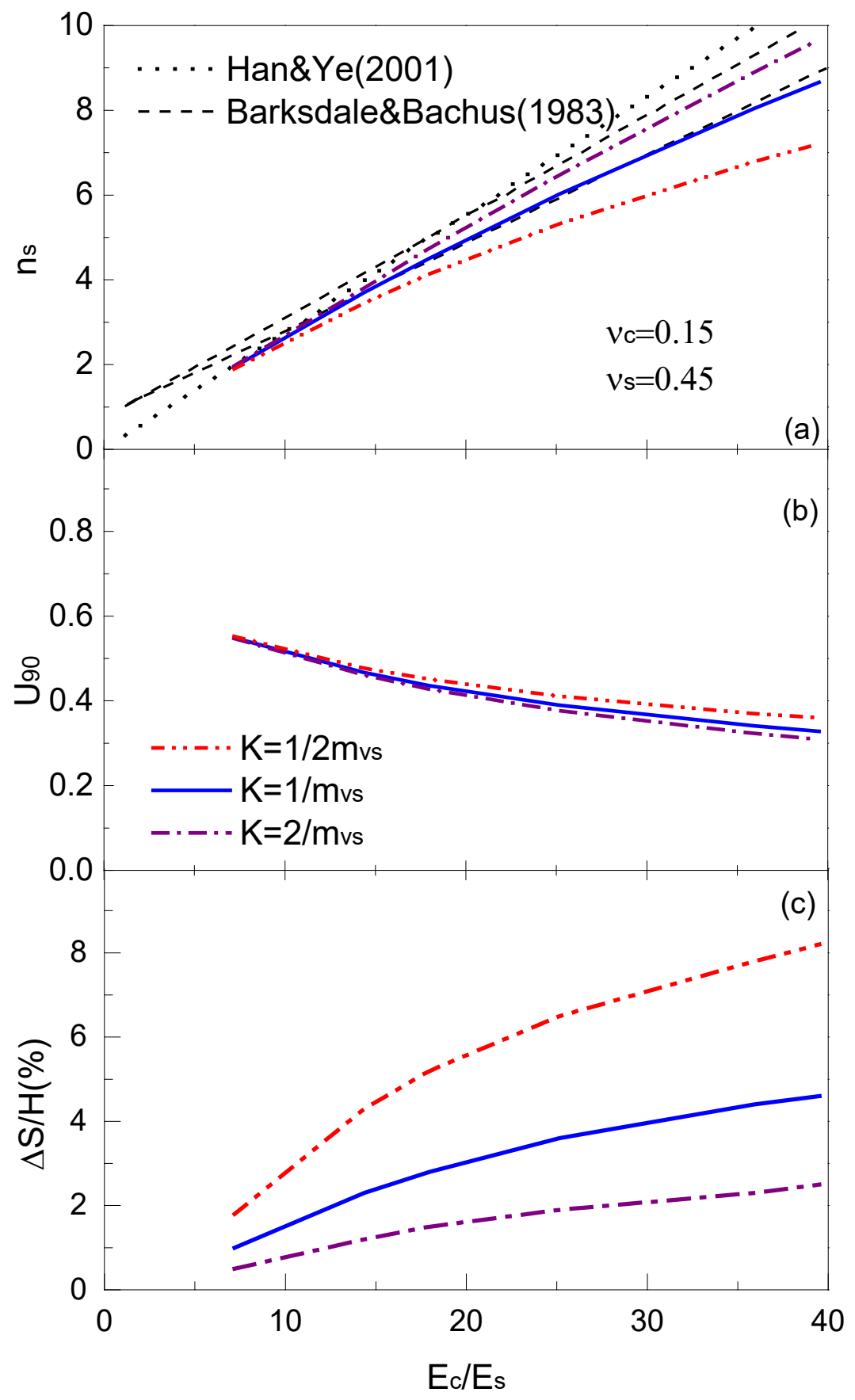

2 Figure 8 Effect of modulus ratio under varying foundation stiffness: (a) steady stress 3 concentration ratio $\left(\mathrm{n}_{\mathrm{s}}\right)$; (b) time to achieve $90 \%$ degree of consolidation $\left(\mathrm{U}_{90}\right)$; (c) 4 differential settlement ratio $(\Delta \mathrm{S} / \mathrm{H})$ 


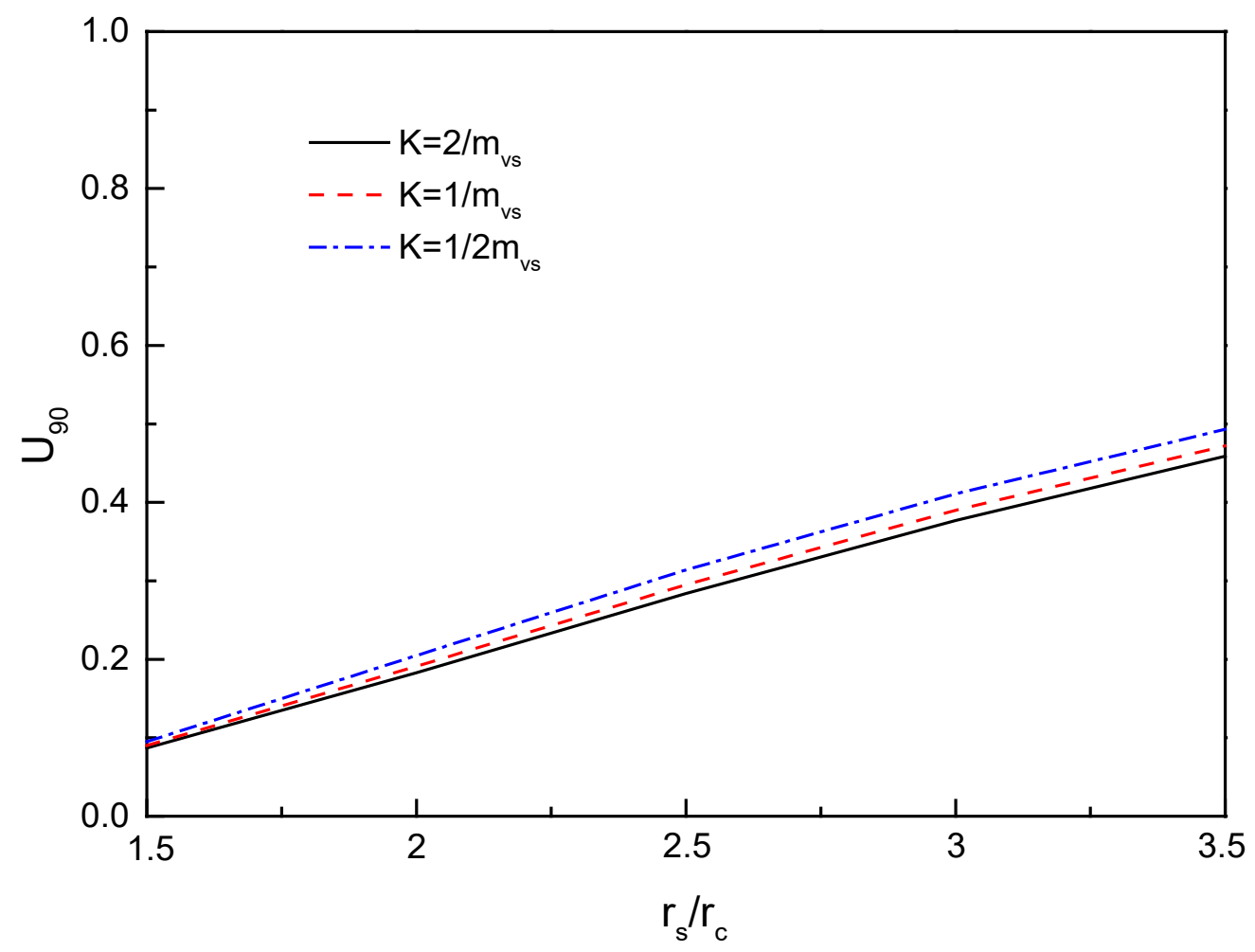

2

(a)

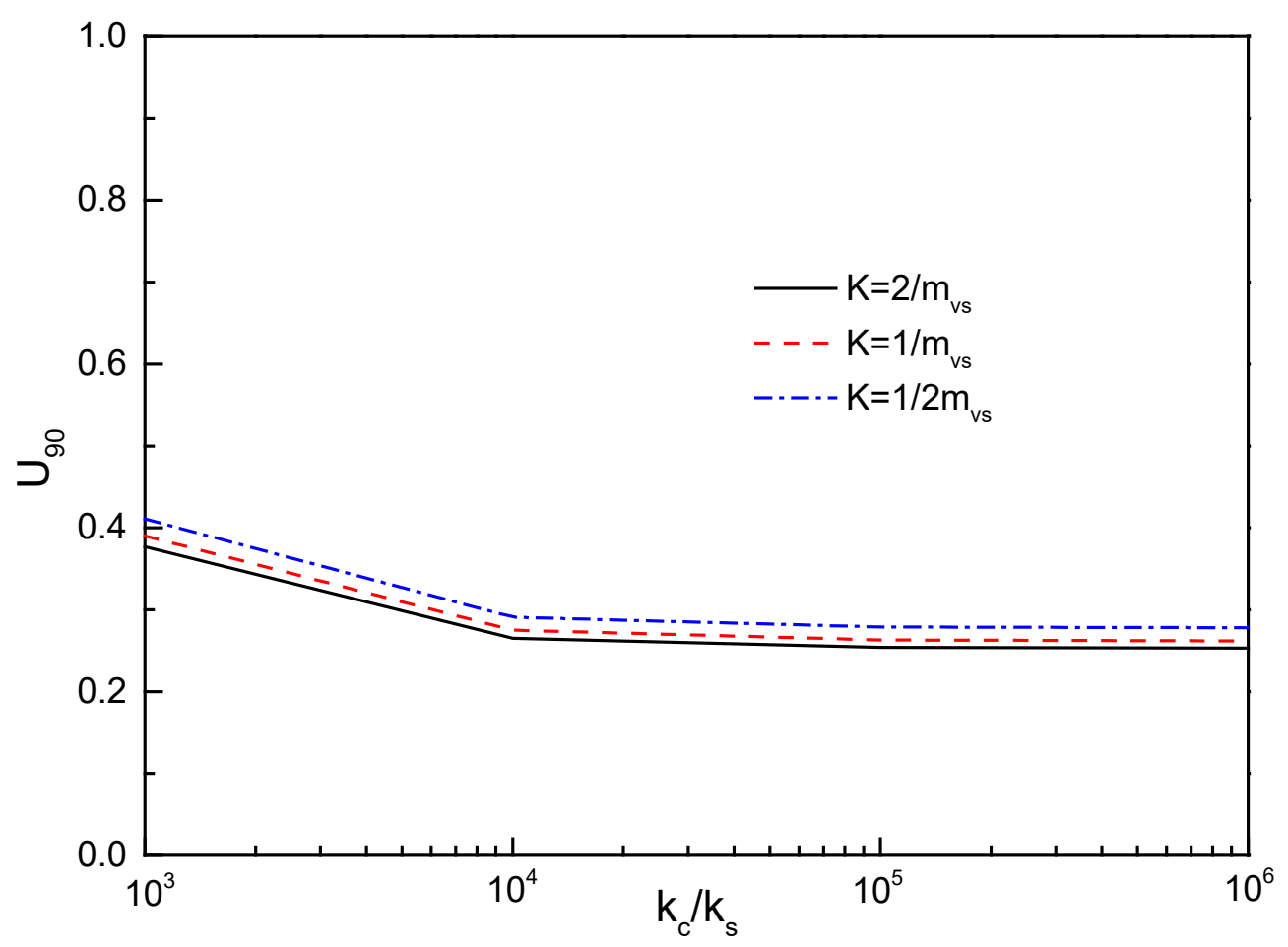

(b)

5 Figure 9 Effect of foundation stiffness on $\mathrm{U}_{90}$ : (a) radius ratio $\left(\mathrm{r}_{\mathrm{s}} / \mathrm{r}_{\mathrm{c}}\right)$; (b) permeability 6 ratio $\left(\mathrm{k}_{\mathrm{c}} / \mathrm{k}_{\mathrm{s}}\right)$ 


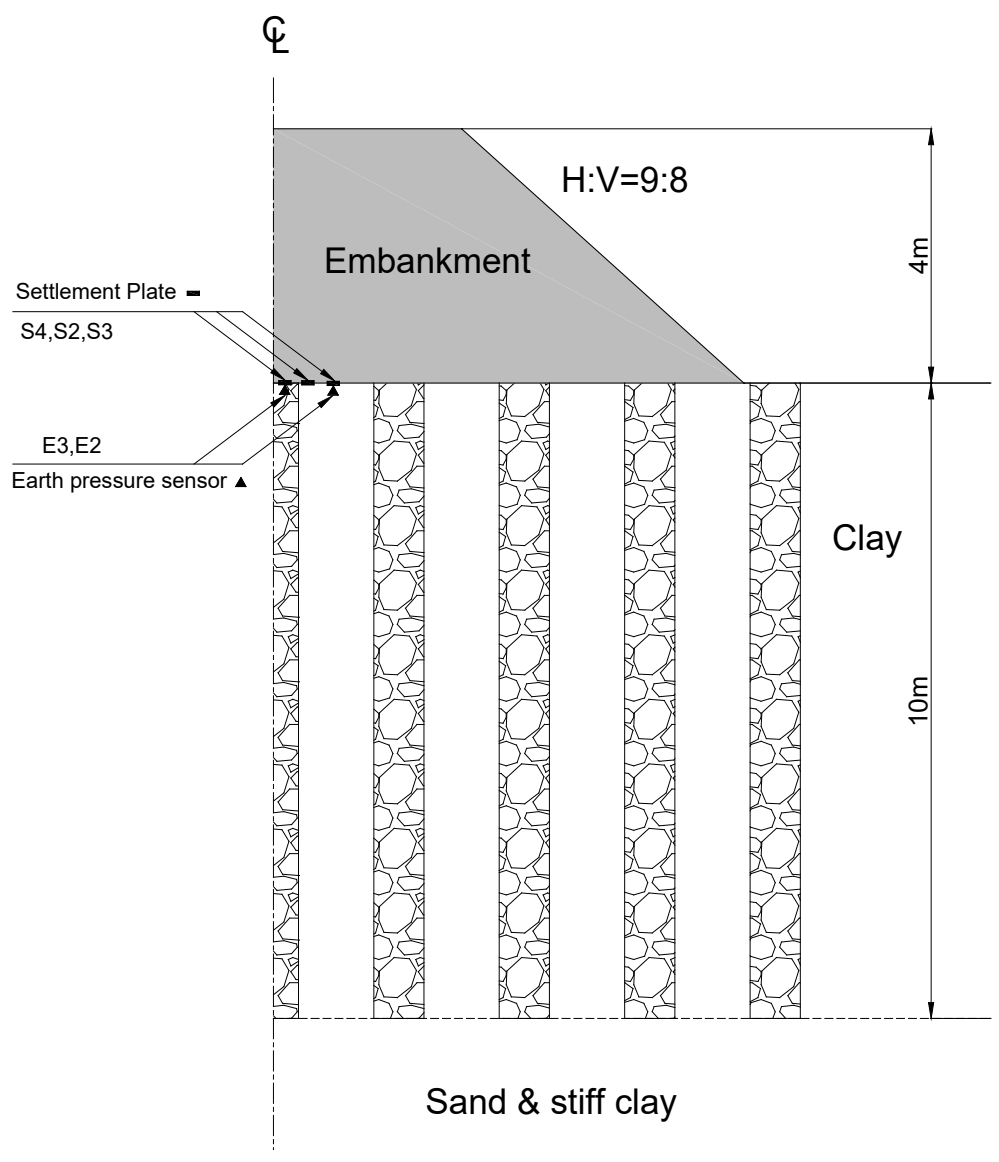

Figure 10 Cross-section of embankment beyond stone columns 3 


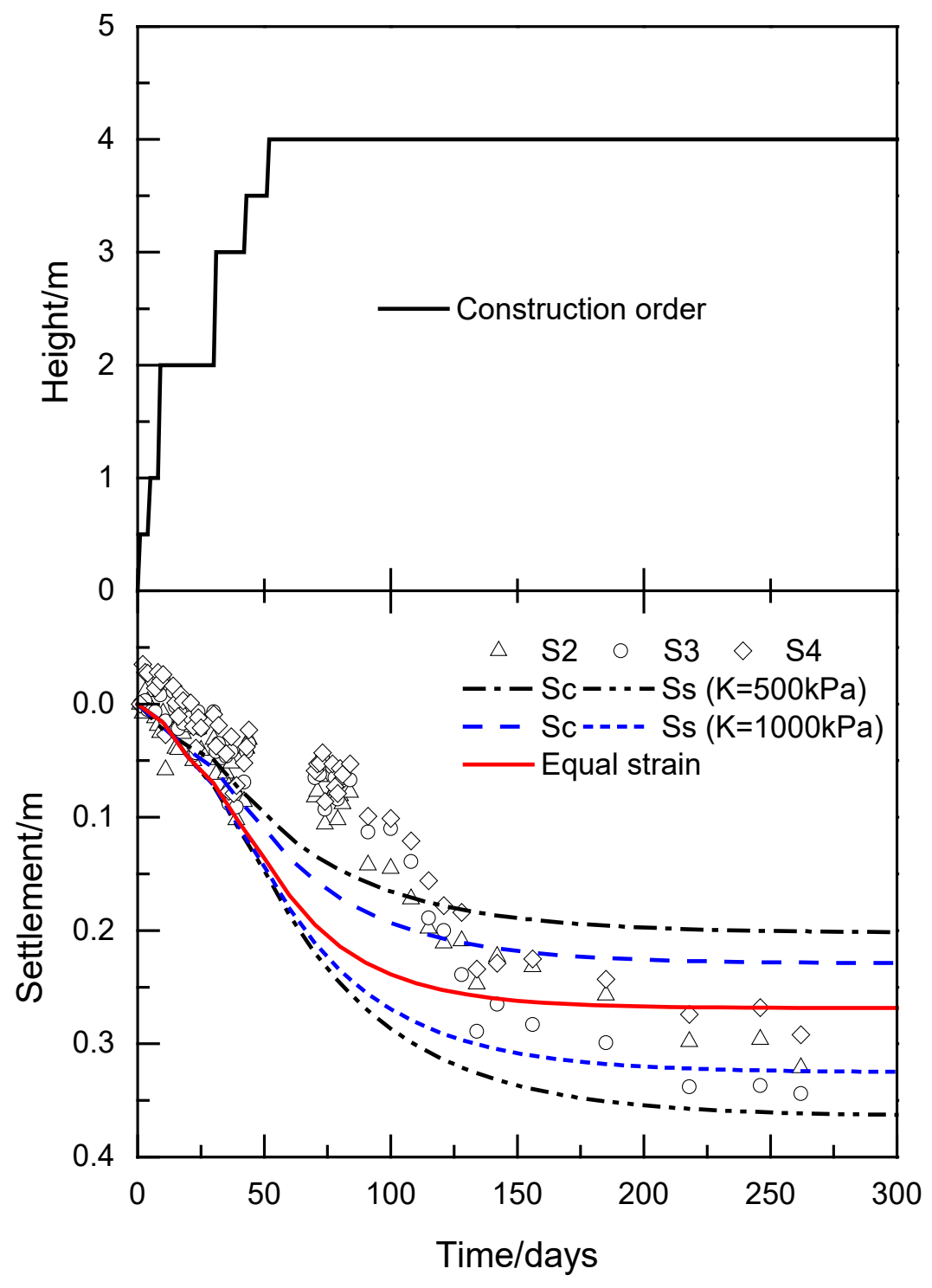

(a)

3 


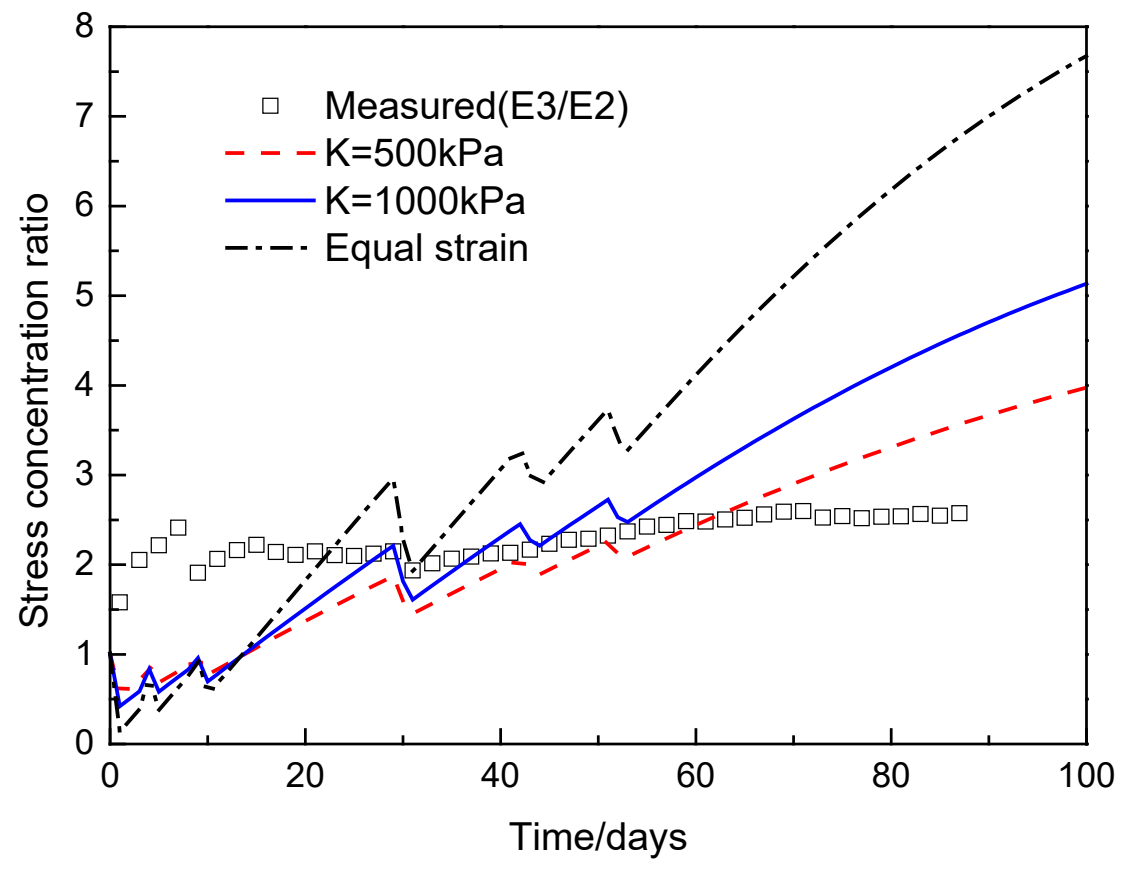

(b)

3 Figure 11 Embankment at Ballina: (a) construction order and settlement; (b) stress 4 concentration ratio 